\title{
Method of determining the degree of liquid aeration in a variable capacity displacement pump
}

\author{
Zygmunt Paszota, Prof. \\ Gdansk University of Technology, Poland
}

\section{ABSTRACT}

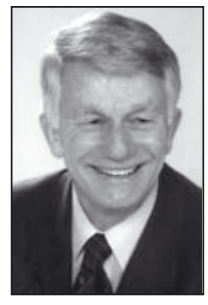

The Author concludes, that there is a possibility of determining a concrete value of the liquid aeration coefficient $\varepsilon$ during the pump operation by finding such value of $\varepsilon$ with which the increase $\Delta M_{P m \mid \Delta p_{P i}}=p_{\eta_{n}} q_{P g y}$ of torque of mechanical losses is proportional to the

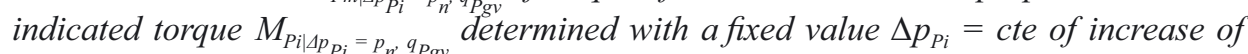
pressure in the pump working chambers. The fixed value $\Delta p_{p_{i}}$ assumed in searching the liquid aeration coefficient $\varepsilon$ equals to the nominal pump operation pressure $p_{n}\left(\Delta p_{P_{i}}=c t e=p_{n}\right)$. The increase $\Delta M_{P_{m} \backslash p_{P_{i}}}=p_{n^{\prime}} q_{P g v}$ of torque of mechanical losses with a fixed value of $\Delta p_{P_{i}}$ $\left(\Delta p_{P i}=c t e\right)$ is proportional to the pump geometrical working capacity $q_{P g v}$, therefore: only with taking into account the aeration coefficient $\varepsilon$ of liquid displaced by the pump the relation $\Delta M_{P_{m} \mid \Delta p_{P i}}=p_{p^{\prime}} q_{P g v} \sim q_{P g v}$ can be obtained from tests. The method, proposed by the Author, of determining the working liquid aeration coefficient $\varepsilon$, is presented in this paper and has been practically applied for the first time by Jan Koralewski in his investigations of the influence of viscosity and compressibility of aerated hydraulic oil on volumetric and mechanical losses in a pump of HYDROMATIK A7V.58.1.R.P.F.00 type [8, 9].

Key words: hydrostatic drive; variable capacity displacement pump; liquid aeration; method of determining the degree of liquid aeration

\section{INTRODUCTION}

In references [1-4] the Author evaluated the effect of working liquid compressibility on the picture of volumetric and mechanical losses in a high-pressure variable capacity displacement pump. The considerations are based on the assumptions made in the, developed by the Author, theoretical and mathematical models of torque of mechanical losses in a pump used in a hydrostatic drive [5 -7]. It is assumed in the models, that increase $\mathrm{M}_{\mathrm{Pi} \mid \Delta \mathrm{p}_{\mathrm{pi}}, \mathrm{q}_{\mathrm{Pgv}}}$ of torque of mechanical losses in the pump ,working chambers - shaft” assembly is proportional to torque $\mathrm{M}_{\mathrm{Pi}}$ indicated in the pump working chambers:

$$
\Delta \mathrm{M}_{\mathrm{Pm} \mid \Delta \mathrm{p}_{\mathrm{Pi}}} \sim \mathrm{M}_{\mathrm{Pi}}
$$

In references [1-4] the Author introduced also a working liquid compressibility coefficient $\mathrm{k}_{\mathrm{lc|} \mathrm{p}_{\mathrm{n}}}$. Coefficient $\mathrm{k}_{\mathrm{kc|} \mathrm{p}_{\mathrm{n}}}$ determines the decrease, as an effect of liquid compressibility, of active volume of working liquid displaced during one pump shaft revolution with the increase $\Delta \mathrm{p}_{\mathrm{Pi}}=\mathrm{p}_{\mathrm{n}}$ of pressure in the working chambers equal to the pump nominal pressure $p_{n}$, compared with active volume equal to theoretical working capacity $\mathrm{q}_{\mathrm{P}_{\mathrm{t}}}$ or geometrical working capacity $\mathrm{q}_{\mathrm{Pg}}$ per one shaft revolution, determined with the increase $\Delta \mathrm{p}_{\mathrm{Pi}}$ of pressure in the working chambers equal to zero $-\Delta \mathrm{p}_{\mathrm{Pi}}=0$ :

$$
\mathrm{k}_{\mathrm{lc} \mid \mathrm{p}_{\mathrm{n}}}=\frac{\mathrm{q}_{\mathrm{Pt}}-\mathrm{q}_{\mathrm{Pt} \mid \Delta \mathrm{p}_{\mathrm{P}}=\mathrm{p}_{\mathrm{n}}}}{\mathrm{q}_{\mathrm{Pt}}}
$$

and

$$
\mathrm{k}_{\mathrm{lc} \mid \mathrm{p}_{\mathrm{n}}}=\frac{\mathrm{q}_{\mathrm{Pgv}}-\mathrm{q}_{\mathrm{Pgv} \mid \Delta \mathrm{p}_{\mathrm{Pi}}=\mathrm{p}_{\mathrm{n}}}}{\mathrm{q}_{\mathrm{Pgv}}}=\frac{\mathrm{b}_{\mathrm{P}} \mathrm{q}_{\mathrm{Pt}}-\mathrm{b}_{\mathrm{P}} \mathrm{q}_{\mathrm{Pt} \mid \Delta \mathrm{p}_{\mathrm{Pi}_{i}}=\mathrm{p}_{\mathrm{n}}}}{\mathrm{b}_{\mathrm{P}} \mathrm{q}_{\mathrm{Pt}}}
$$

The Author has also concluded that it is possible to evaluate the effect of liquid compressibility coefficient $\mathrm{k}_{\mathrm{lc|}_{\mathrm{n}}}$ on the value of increase $\Delta \mathrm{M}_{\mathrm{P}_{\mathrm{m}} / \Delta \mathrm{p}_{\mathrm{Pi}}=\mathrm{p}_{\mathrm{n}^{\prime}}, \mathrm{q}_{\mathrm{pgv}}}$ of torque of mechanical losses in the pump ,working chambers - shaft" assembly and to evaluate the effect of $k_{\mathrm{lc|} p_{n}}$ coefficient on the value of the coefficient of volumetric losses in the pump working chambers due to leakage. 
Searching the value of liquid compressibility coefficient $\mathrm{k}_{\mathrm{Ic|} \mathrm{p}_{\mathrm{n}}}$, which with the increase $\Delta \mathrm{p}_{\mathrm{Pi}}$ of pressure in working chambers, equal to the pump nominal pressure $\mathrm{p}_{\mathrm{n}}$, will cause an increase $\Delta \mathrm{M}_{\mathrm{Pm}_{\mathrm{m}} \Delta \mathrm{p}_{\mathrm{Pi}}}=\mathrm{p}_{\mathrm{n}^{\prime}}, \mathrm{q}_{\mathrm{pgv}}$ of torque of mechanical losses proportional to $\mathrm{q}_{\mathrm{Pgv}}$, i.e. to the indicated torque $\mathrm{M}_{\mathrm{Pi} \mid \Delta \mathrm{p}_{\mathrm{Pi}}=\mathrm{p}_{\mathrm{n}}, \mathrm{q}_{\mathrm{pgv}}}$ the Author determined, in the pump HYDROMATIK A7V.58.1.R.P.F.00 type, tested by Jan Koralewski in his doctor dissertation [8] the approximate value of the oil compressibility coefficient during the tests as equal to $\mathrm{k}_{\mathrm{lc} 32 \mathrm{MPa}}=0.030$.

Taking into account the working liquid compressibility evaluated by the coefficient $\mathrm{k}_{\mathrm{lc} \mid 32 \mathrm{MPa}}=0.030$. Author determined approximate values of new coefficients of volumetric and mechanical losses in the tested pump.

The Author concludes, that there is a possibility of determining a concrete value of the liquid aeration coefficient $\varepsilon$ during the pump operation by finding such value of $\varepsilon$ with which the increase $\Delta \mathrm{M}_{\mathrm{Pm}_{\mathrm{m}} / \mathrm{p}_{\mathrm{pi}}=\mathrm{p}_{\mathrm{n}}, \mathrm{q}_{\mathrm{ggv}}}$ of torque of mechanical losses is proportional to the indicated torque $\mathrm{M}_{\mathrm{Pi}}\left\langle\Delta \mathrm{p}_{\mathrm{pi}}=\mathrm{p}_{\mathrm{n}}, \mathrm{q}_{\mathrm{pgv}}\right.$ determined with a fixed value $\Delta \mathrm{p}_{\mathrm{Pi}}=$ cte of increase of pressure in the pump working chambers. The fixed value $\Delta \mathrm{p}_{\mathrm{pi}}$ assumed in searching the liquid aeration coefficient $\varepsilon$ equals to the nominal pump operation pressure $\mathrm{p}_{\mathrm{n}}\left(\Delta \mathrm{p}_{\mathrm{Pi}}=\right.$ cte $\left.=\mathrm{p}_{\mathrm{n}}\right)$.

The increase $\Delta \mathrm{M}_{\mathrm{Pm} \backslash \Delta \mathrm{p}_{\mathrm{p}}=\mathrm{p}_{\mathrm{n}}, \mathrm{q}_{\mathrm{pgv}}}$ of torque of mechanical losses with a fixed value of $\Delta \mathrm{p}_{\mathrm{pi}}\left(\Delta \mathrm{p}_{\mathrm{Pi}}=\right.$ cte $)$ is proportional to the pump geometrical working capacity $\mathrm{q}_{\mathrm{Pgv}}$, therefore:

only with taking into account the aeration coefficient $\varepsilon$ of liquid displaced by the pump the relation $\Delta \mathrm{M}_{\mathrm{P}_{\mathrm{P} /} / \mathrm{p}_{\mathrm{Pi}}}=\mathrm{p}_{\mathrm{n}}, \mathrm{q}_{\mathrm{Pgv}} \sim \mathbf{q}_{\mathrm{Pgv}}$ can be obtained from tests.

The method, proposed by the Author, of determining the working liquid aeration coefficient $\varepsilon$, is presented in this paper and has been practically applied for the first time by Jan Koralewski in his investigations of the influence of viscosity and compressibility of aerated hydraulic oil on volumetric and mechanical losses in a pump of HYDROMATIK A7V.58.1.R.P.F.00 type $[8,9]$.

\section{COMPRESSIBILITY OF WORKING LIQUID IN THE PUMP}

Compressibility of liquid at a given temperature is characterized by variation of its mass density $\rho$ as a function of pressure $\mathrm{p}$. In order to facilitate the calculations, the curve of variation $\rho=f(p)$ is represented by an approximate algebraic relation. Most often a linear approximation is used:

$$
\frac{\Delta \rho}{\rho}=\frac{\Delta p}{B}
$$

It may be said, that relation (1) defines a modulus $\mathbf{B}$ of the liquid volume elasticity valid for a certain temperature and for a certain pressure.

Numerical indications regarding the value of B of hydraulic oils are the following [10]:

- at the normal temperature $\left(20^{\circ} \mathrm{C}\right)$, close to $\mathrm{B}=1500 \mathrm{MPa}$ for the used hydraulic oils,

- B increases with the pressure (by about $1 \%$ every $2 \mathrm{MPa}$ up to $20 \mathrm{MPa}$ for the used oils $\left(\mathrm{a}_{\mathrm{p}}=0.005 / 1 \mathrm{MPa}\right)$ ),
- B decreases when the temperature increases (about $1 \%$ every $2{ }^{\circ} \mathrm{C}$ up to $100^{\circ} \mathrm{C}$ for the used oils $\left(\mathrm{a}_{\vartheta}=-0.005 / 1{ }^{\circ} \mathrm{C}\right)$ ).

In working chambers of the tested piston pump [8,9], during their connection with the inlet channel, was slight overpressure $\mathrm{p}_{\mathrm{Pli}} \approx 0.05 \mathrm{MPa}$ (i.e. absolute pressure $\mathrm{p}_{\mathrm{Plia}} \approx 0.15 \mathrm{MPa}$ ). Let's assume that the value of modulus $\mathrm{B}$ of the hydraulic oil volume elasticity, at the temperature $\vartheta=20^{\circ} \mathrm{C}$, equals to:

$$
\mathrm{B}_{\mid \mathrm{p}_{\text {Plia }} \approx 0.15 \mathrm{Mpa} ; \vartheta=20^{\circ} \mathrm{C}}=1500 \mathrm{MPa}
$$

Therefore, the dependence of modulus $B$ of oil on the increase $\Delta \mathrm{p}_{\mathrm{Pi}}$ of pressure in the working chambers and on the increase $\Delta \vartheta$ of oil temperature may be described by the expression:

$$
\mathrm{B}=\mathrm{B}_{\mid \mathrm{p}_{\text {Plia }} \approx 0.15 \mathrm{Mpa} ; \vartheta=20^{\circ} \mathrm{C}}\left(1+\mathrm{a}_{\mathrm{p}} \Delta \mathrm{p}_{\mathrm{Pi}}+\mathrm{a}_{\vartheta} \Delta \vartheta\right)
$$

Modulus B of hydraulic oil volume elasticity decreases very quickly when oil is aerated, i.e. when the oil aeration coefficient $\varepsilon$ is greater than zero $(\varepsilon>0)$.

The oil aeration coefficient $\varepsilon$ is the ratio of volume $V_{a}$ of air to volume $\mathrm{V}_{0}=\mathrm{V}_{\mathrm{o}}+\mathrm{V}_{\mathrm{a}}$ of mixture of oil volume $\mathrm{V}_{\mathrm{o}}$ and air volume $\mathrm{V}_{\mathrm{a}}\left(\varepsilon=\mathrm{V}_{\mathrm{a}} / \mathrm{V}_{0}=\mathrm{V}_{\mathrm{a}} /\left(\mathrm{V}_{\mathrm{o}}+\mathrm{V}_{\mathrm{a}}\right)\right)$. The oil aeration coefficient $\varepsilon$ is determined at the absolute pressure $\mathrm{p}_{\text {Plia }}$ in the pump working chambers during their connection with the inlet channel.

Let's suppose, that volume $\mathrm{V}_{0}$ of aerated oil in the pump working chambers, at initial absolute pressure $\mathrm{p}_{\mathrm{Plia}}$ in the chambers (Fig. 6), contains a volume of air equal $\mathrm{V}_{\mathrm{a}}=\varepsilon \mathrm{V}_{0}$ and a volume of oil equal $\mathrm{V}_{\mathrm{o}}=(1-\varepsilon) \mathrm{V}_{0}$.

An increase $\Delta \mathrm{p}_{\mathrm{pi}}$ of pressure in the pump working chambers causes a decrease of the oil and air mixture volume by the value $\Delta \mathrm{V}$ (assuming a hypothesis of compression of air $\mathrm{pV}_{\mathrm{a}}=$ cte) equal to:

$$
\Delta \mathrm{V}=\Delta \mathrm{V}_{\mathrm{o}}+\Delta \mathrm{V}_{\mathrm{a}}=\frac{\mathrm{V}_{\mathrm{o}}}{\mathrm{B}} \Delta \mathrm{p}_{\mathrm{Pi}}+\frac{\mathrm{V}_{\mathrm{a}}}{\mathrm{p}_{\mathrm{Plia}}+\Delta \mathrm{p}_{\mathrm{Pi}}} \Delta \mathrm{p}_{\mathrm{Pi}}
$$

If the aeration coefficient $\varepsilon$ is small, which is a general case, $V_{0}$ is close to $V_{0}$. Therefore it can be written:

$$
\Delta \mathrm{V}=\mathrm{V}_{0}\left(\frac{1}{\mathrm{~B}}+\frac{\varepsilon}{\mathrm{p}_{\mathrm{Plia}}+\Delta \mathrm{p}_{\mathrm{Pi}}}\right) \Delta \mathrm{p}_{\mathrm{Pi}}
$$

Therefore, with the oil aeration coefficient $\varepsilon$ greater than zero $(\varepsilon>0)$, modulus $B$ of oil volume elasticity must be replaced by modulus $B$ ' of volume elasticity defined by the relation:

$$
\frac{1}{\mathrm{~B}^{\prime}}=\frac{1}{\mathrm{~B}}+\frac{\varepsilon}{\mathrm{p}_{\mathrm{P} 1 \mathrm{ia}}+\Delta \mathrm{p}_{\mathrm{Pi}}}
$$

or, in the conditions of changing pressure and temperature of the aerated oil, by the relation:

$$
\begin{gathered}
\frac{1}{\mathrm{~B}^{\prime}}=\frac{1}{\mathrm{~B}_{\mid \mathrm{p}_{\mathrm{Plia}} \approx 0.15 \mathrm{MPa}, \vartheta=20^{\circ} \mathrm{C}}\left(1+\mathrm{a}_{\mathrm{p}} \Delta \mathrm{p}_{\mathrm{Pi}}+\mathrm{a}_{\vartheta} \Delta \vartheta\right)}+ \\
+\frac{\varepsilon}{\mathrm{p}_{\mathrm{P} 1 \mathrm{ia}}+\Delta \mathrm{p}_{\mathrm{Pi}}}
\end{gathered}
$$




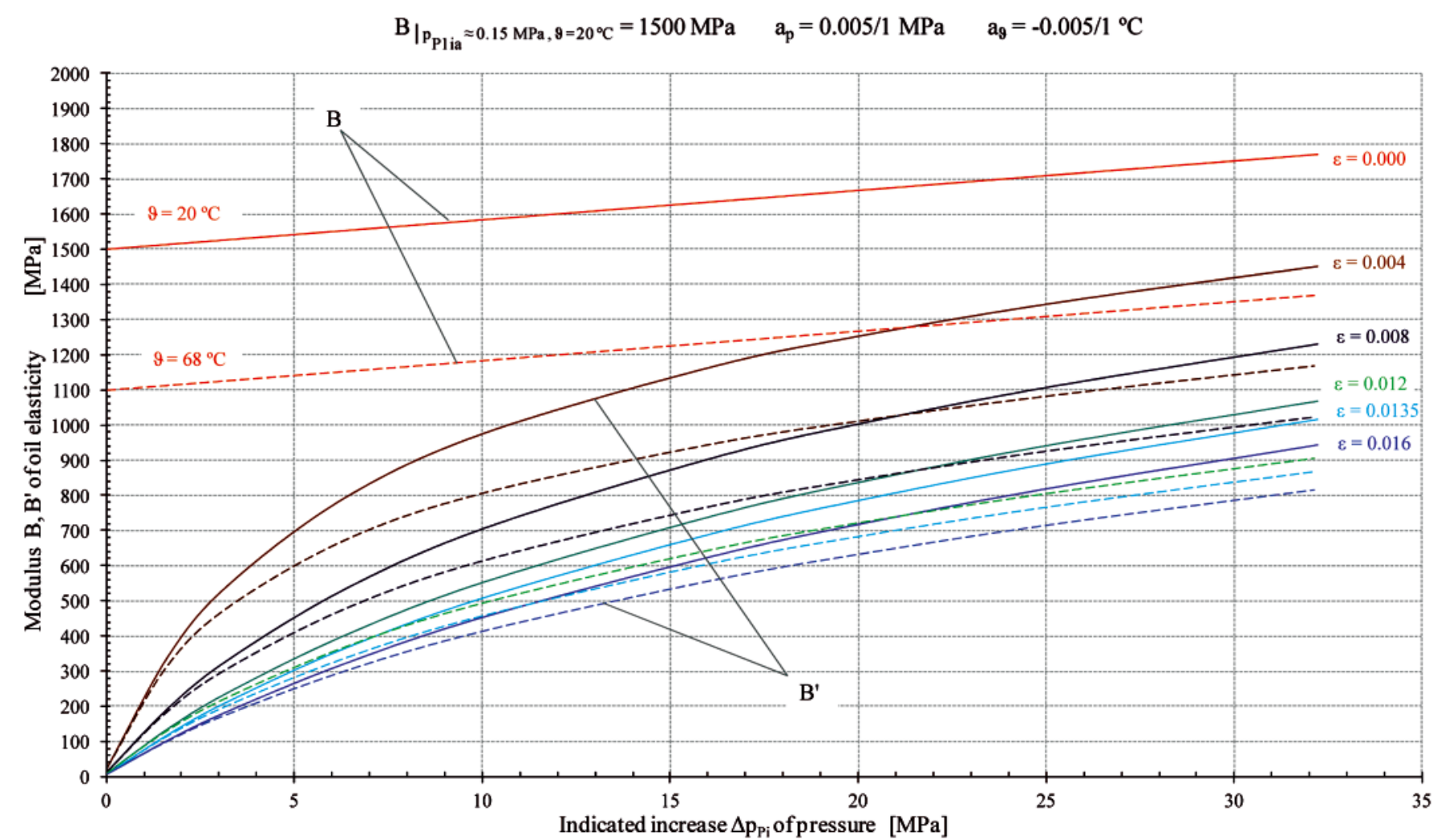

Fig. 1. Modulus $B$ of volume elasticity of non-aerated hydraulic oil $(\varepsilon=0)$ and modulus B' of aerated oil $(\varepsilon>0)$ as relations dependent on indicated increase $\Delta p_{P i}$ of pressure in the pump working chambers, with limit values $\vartheta=20^{\circ} \mathrm{C}$ (continuous line) and $\vartheta=68^{\circ} \mathrm{C}$ (dashed line) of hydraulic oil temperature adopted during the investigations [8, 9]. It was assumed that modulus $B$ of oil volume elasticity at absolute pressure $p_{P l i a} \approx 0.15$ MPa in the pump working chambers during their connection with the inlet channel and at oil temperature $\vartheta=20^{\circ} \mathrm{C}$ is equal to $\mathrm{B}=1500 \mathrm{MPa}$. Also assumed was the value of coefficient $a_{p}=0.005 / 1 \mathrm{MPa}$ of the change of modulus $B$ of oil due to increase $\Delta p_{P i}$ of pressure in the working channels and coefficient $a_{\vartheta}=-0.005 / 1{ }^{\circ} \mathrm{C}$ of the change of modulus $B$ due to change of oil temperature $\vartheta$

Fig. 1 presents the modulus B of volume elasticity of non-aerated hydraulic oil $(\varepsilon=0)$ and modulus B' of aerated oil $(\varepsilon>0)$ as relations dependent on indicated increase $\Delta \mathrm{p}_{\mathrm{Pi}}$ of pressure in the pump working chambers, with limit values $\vartheta=20^{\circ} \mathrm{C}$ and $\vartheta=68^{\circ} \mathrm{C}$ of oil temperature adopted during the investigations $[8,9]$.

The displacement pump with variable geometric working capacity $q_{\mathrm{pgv}}$ per one shaft revolution is tested with different fixed values of $q_{\mathrm{Pgv}}$.

Variable (set during the test) geometrical working capacity $\mathrm{q}_{\mathrm{Pgv}}$ of working chambers per one shaft revolution equals to the difference between maximum chambers capacity (capacity increasing to that maximum value during connection of the chamber with the pump inlet channel) and minimum chamber capacity (capacity decreasing to that value during connection of the chambers with the pump outlet (discharge) channel). The initial volume $\mathrm{V}_{0}$ of oil (Fig. 6), which is compressed due to increase $\Delta \mathrm{p}_{\mathrm{Pi}}$ of pressure in the pump chambers, corresponding to setting $\mathrm{q}_{\mathrm{pg}}$ of the variable geometrical working capacity, is in a variable capacity pump equal to:

$$
\mathrm{V}_{0}=0.5 \mathrm{q}_{\mathrm{Pt}}+0.5 \mathrm{q}_{\mathrm{Pgv}}
$$

When the variable (set) geometrical working capacity $\mathrm{q}_{\mathrm{pgv}}$ reaches the maximum value equal to the pump theoretical working capacity $\mathrm{q}_{\mathrm{Pt}}\left(\mathrm{q}_{\mathrm{Pgv}}=\mathrm{q}_{\mathrm{Pt}}\right)$, volume $\mathrm{V}_{0}$ of compressed oil is equal to:

$$
\mathrm{V}_{0}=0.5 \mathrm{q}_{\mathrm{Pt}}+0.5 \mathrm{q}_{\mathrm{Pt}}=\mathrm{q}_{\mathrm{Pt}}
$$

The change $\Delta \mathrm{V}$ of liquid volume (Fig. 6), due to the liquid compression under the increase $\Delta \mathrm{p}_{\mathrm{pi}}$ of pressure in the pump chambers, is equal to the loss $\mathrm{q}_{\mathrm{Pvc}}$ of pump capacity per one shaft revolution:

$$
\Delta \mathrm{V}=\mathrm{q}_{\mathrm{Pvc}}
$$

The loss $\mathrm{q}_{\mathrm{Pvc}}$ of pump capacity per one shaft revolution (Fig. 2), resulting from the compression of non-aerated (or aerated) oil at the setting $\mathrm{q}_{\mathrm{Pgv}}$ of geometrical variable working capacity, is determined (in reference to (5) and (6)) by the expression:

$$
\mathrm{q}_{\mathrm{Pvc}}=\frac{\left(0.5 \mathrm{q}_{\mathrm{Pt}}+0.5 \mathrm{q}_{\mathrm{Pt}}\right) \Delta \mathrm{p}_{\mathrm{Pi}}}{\mathrm{B}^{\prime}}
$$

and with $\mathrm{q}_{\mathrm{Pgv}}=\mathrm{q}_{\mathrm{Pt}}$, by expression:

$$
\mathrm{q}_{\mathrm{Pvc}}=\frac{\mathrm{q}_{\mathrm{Pt}} \Delta \mathrm{p}_{\mathrm{Pi}}}{\mathrm{B}^{\prime}}
$$

and, after replacing 1/B' by expression (7), by the formula:

$$
\mathrm{q}_{\mathrm{Pvc}}=\left(0.5 \mathrm{q}_{\mathrm{Pt}}+0.5 \mathrm{q}_{\mathrm{Pgv}}\right) \text {. }
$$

$$
\left[\begin{array}{c}
\frac{1}{\mathrm{~B}_{\mid \mathrm{p}_{\mathrm{Pli}} \approx 0.15 \mathrm{MPa}, 9=20{ }^{\circ} \mathrm{C}}\left(1+\mathrm{a}_{\mathrm{p}} \Delta \mathrm{p}_{\mathrm{Pi}}+\mathrm{a}_{9} \Delta \vartheta\right)}+ \\
+\frac{\varepsilon}{\mathrm{p}_{\mathrm{Plia}}+\Delta \mathrm{p}_{\mathrm{Pi}}}
\end{array}\right] \Delta \mathrm{p}_{\mathrm{Pi}}
$$




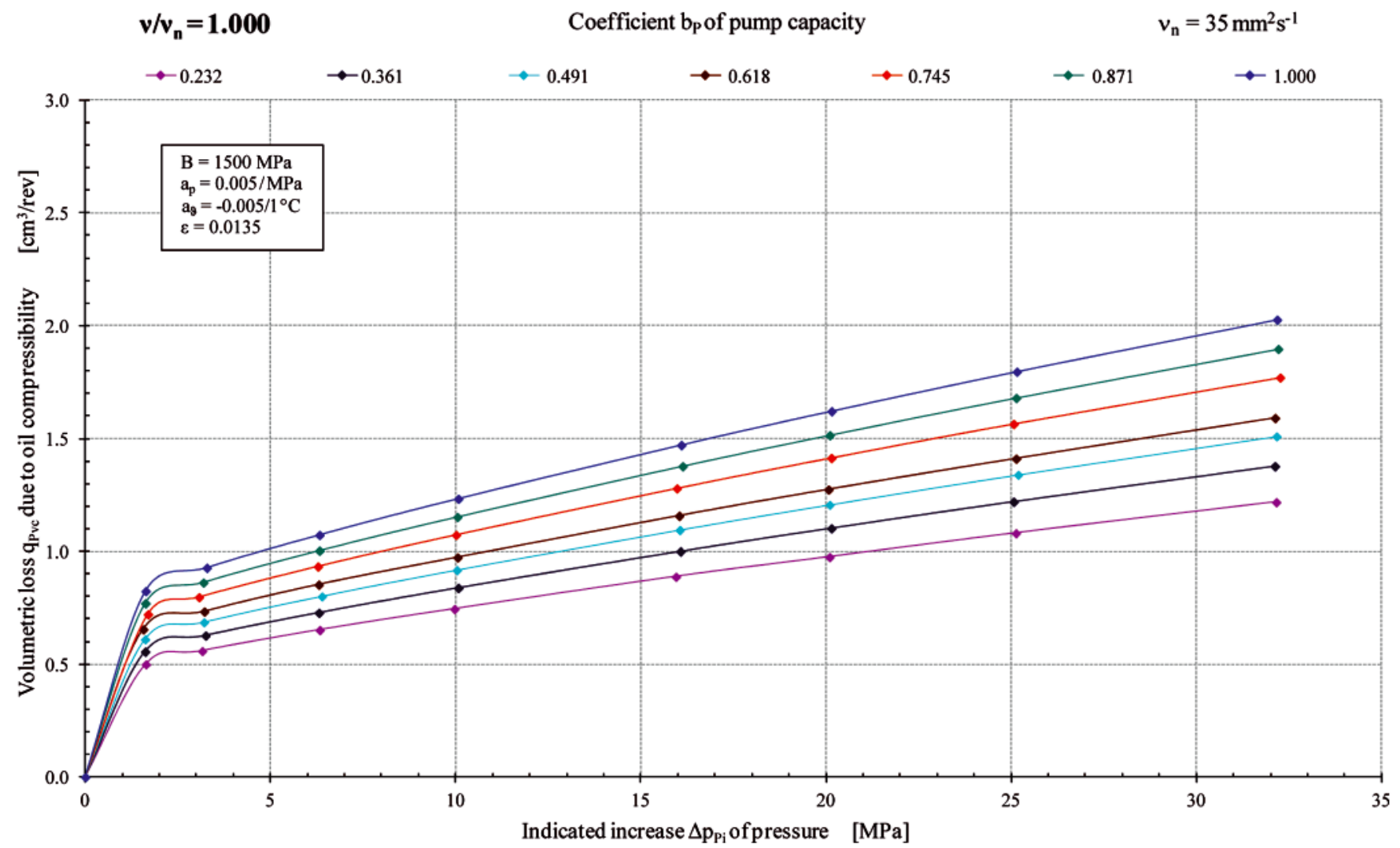

Fig. 2. Loss $q_{P v c}$ of pump capacity during one pump shaft revolution due to compressibility of aerated $(\varepsilon=0.0135)$ liquid, decreasing the active volume of liquid displaced by the pump compared with the theoretical working capacity $q_{P t}\left(b_{P}=1\right)$ or geometrical working capacity $q_{P g v}\left(0<b_{P}<1\right)($ pump of HYDROMATIK A7V.DR.1.R.P.F.00 type) [8,9]

and also, with $\mathrm{q}_{\mathrm{Pgv}}=\mathrm{q}_{\mathrm{Pt}}$, by the formula:

$$
\mathrm{q}_{\mathrm{Pvc}}=\mathrm{q}_{\mathrm{Pt}} \text {. }
$$

$$
\left[\frac{1}{\mathrm{~B}_{\mathrm{p}_{\mathrm{P} \text { lia }} \approx 0.15 \mathrm{MPa}, \vartheta=20^{\circ} \mathrm{C}}\left(1+\mathrm{a}_{\mathrm{p}} \Delta \mathrm{p}_{\mathrm{Pi}}+\mathrm{a}_{\vartheta} \Delta \vartheta\right)}+\frac{\varepsilon}{+\frac{\varepsilon}{\mathrm{p}_{\mathrm{P} \text { lia }}+\Delta \mathrm{p}_{\mathrm{Pi}}}}\right] \Delta \mathrm{p}_{\mathrm{Pi}}
$$

Fig. 2 presents an example (with assumed oil aeration coefficient $\varepsilon=0.0135$ ) of the results of calculations of the loss $\mathrm{q}_{\mathrm{Pvc}}=\mathrm{f}\left(\Delta \mathrm{p}_{\mathrm{Pi}}\right)$ of the tested pump capacity per one shaft revolution, taking into account formula (13) for setting $\mathrm{q}_{\mathrm{Pgv}}$ of the geometrical variable working capacity and formula (14) for the maximum setting $\mathrm{q}_{\mathrm{Pgv}}=\mathrm{q}_{\mathrm{Pt}}$, i.e. the case of pump theoretical working capacity.

The change of $\mathrm{q}_{\mathrm{Pvc}}$ as a function of indicated increase $\Delta \mathrm{p}_{\mathrm{Pi}}$ of pressure in the working chambers, presented in Fig. 2, takes into account the influence of changing volumes $\mathrm{V}_{0}$ (Fig. 6) of compressed liquid in the working chambers, the changes being an effect of the principle of operation of a variable capacity $q_{\mathrm{Pgv}}$ per one shaft revolution displacement pump (with variable $b_{P}$ coefficient).

Loss $\mathrm{q}_{\mathrm{Pvc}}$ of pump capacity during one shaft revolution due to the liquid compressibility decreases the active liquid volume displaced by the pump compared with the theoretical working capacity $\mathrm{q}_{\mathrm{Pt}}$ or geometrical variable working capacity $\mathrm{q}_{\mathrm{Pgv}}$ (determined at $\Delta \mathrm{p}_{\mathrm{Pi}}=0$ ). This fact should be taken into account in the evaluation of intensity $\mathrm{q}_{\mathrm{Pv}}=\mathrm{Q}_{\mathrm{Pv}} / \mathrm{n}_{\mathrm{P}}$ of volumetric losses in the working chambers as well as in the evaluation of increase $\Delta \mathrm{M}_{\mathrm{Pm} \mid \Delta \mathrm{p}_{\mathrm{Pi}}}$ of the torque of mechanical losses in the ,working chambers - shaft" assembly, the losses caused by the increase $\Delta \mathrm{p}_{\mathrm{Pi}}$ of pressure in the pump working chambers with determined values of the chamber geometrical working capacity $\mathrm{q}_{\mathrm{Pgv}}$.

In the considerations, notions have been introduced of theoretical active working capacity $q_{P t \mid \Delta p_{P i}}=p_{n}$ and of geometrical active working capacity $\mathrm{q}_{\mathrm{Pgv} \mid \Delta \mathrm{p}_{\mathrm{Pi}}=\mathrm{p}_{\mathrm{n}}}$ as capacities the pump has in the working chambers at the increase $\Delta \mathbf{p}_{\mathrm{Pi}}$ of pressure in the chambers equal to the nominal pressure $\mathbf{p}_{\mathbf{n}}$ of system operation. The active working capacities $\mathrm{q}_{\mathrm{P} t \mid \Delta \mathrm{p}_{\mathrm{Pi}}}=$ $\mathrm{p}_{\mathrm{n}}$ and $\mathrm{q}_{\mathrm{Pgv} \mid \Delta \mathrm{p}_{\mathrm{Pi}}}=\mathrm{p}_{\mathrm{n}}$ can be determined from the equations:

$$
\begin{gathered}
\mathrm{q}_{\mathrm{Pt} \mid \Delta \mathrm{p}_{\mathrm{Pi}}=\mathrm{p}_{\mathrm{n}}}=\mathrm{q}_{\mathrm{Pt}}-\mathrm{q}_{\mathrm{Pvc} \mid \mathrm{p}_{\mathrm{n}}} \\
\mathrm{q}_{\mathrm{Pgv} \mid \Delta \mathrm{p}_{\mathrm{Pi}}=\mathrm{p}_{\mathrm{n}}}=\mathrm{q}_{\mathrm{Pgv}}-\mathrm{q}_{\mathrm{Pvc} \mid \mathrm{p}_{\mathrm{n}}}
\end{gathered}
$$

Also a notion has been introduced of the coefficient $\mathbf{k}_{\mathbf{l c} \mid \mathbf{p}_{\mathbf{n}}}$ of working liquid compressibility in the pump.

Coefficient $k_{\mathrm{lc} \mid p_{n}}$ of the working liquid compressibility in the pump determines the degree of decrease, as an effect of liquid compressibility (without taking into account the chamber leakage), of the liquid active volume displaced by the pump during one shaft revolution at the increase $\Delta \mathbf{p}_{\mathrm{Pi}}$ of pressure in the pump working chambers equal to the nominal pressure $p_{n}$ of system operation, compared with the active volume displaced by the pump at $\Delta \mathbf{p}_{\mathrm{Pi}}=\mathbf{0}$. Coefficient $\mathrm{k}_{\mathrm{lc|} \mathrm{p}_{\mathrm{n}}}$ is defined by the formulae: 


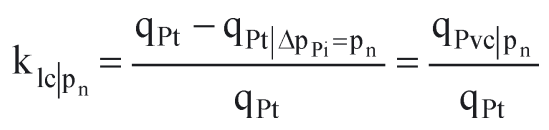

or:

$$
\mathrm{k}_{\mathrm{lc} \mid \mathrm{p}_{\mathrm{n}}}=\frac{\mathrm{q}_{\text {Pgv }}-\mathrm{q}_{\text {Pgv } \mid \Delta \mathrm{p}_{\mathrm{P}_{\mathrm{i}}}=\mathrm{p}_{\mathrm{n}}}}{\mathrm{q}_{\text {Pgv }}}=\frac{\mathrm{q}_{\text {Pvc } \mid \mathrm{p}_{\mathrm{n}}}}{\mathrm{q}_{\text {Pvg }}}
$$

The knowledge of coefficient $k_{\mathrm{lc} \mid \mathrm{p}_{\mathrm{n}}}$ of the liquid compressibility in the pump allows to evaluate numerically the subdivision of volumetric losses in the pump into the losses due to oil leakage in the working chambers and losses due to liquid compressibility.

In a variable capacity pump operating with setting $\mathrm{q}_{\mathrm{Pgv}}$ of geometrical variable working capacity (determined at $\Delta \mathrm{p}_{\mathrm{Pi}}=0$ ), the coefficient $\mathrm{k}_{\mathrm{Icp}_{\mathrm{n}}}$ is described (in reference to (13) and (18)) by the formula:

$$
\begin{aligned}
& \mathrm{k}_{\mathrm{lc} \mid \mathrm{p}_{\mathrm{n}}}=\frac{\mathrm{q}_{\mathrm{Pvd} \Delta \mathrm{p}_{\mathrm{Pi}}=\mathrm{p}_{\mathrm{n}}}}{\mathrm{q}_{\mathrm{Pgv}}}=\frac{0.5 \mathrm{q}_{\mathrm{Pt}}+0.5 \mathrm{q}_{\mathrm{Pgv}}}{\mathrm{q}_{\mathrm{Pgv}}} .
\end{aligned}
$$

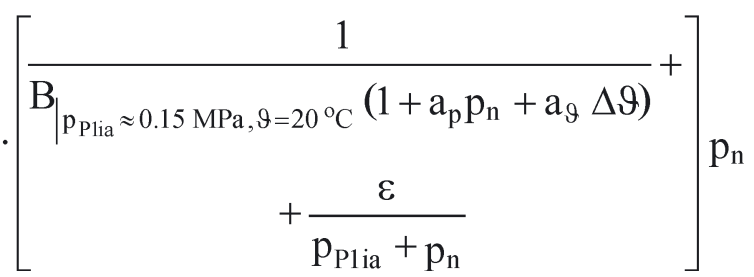

and with $\mathrm{q}_{\mathrm{Pgv}}=\mathrm{q}_{\mathrm{Pt}}$ (in reference to (14) and (17)) by the formula:

$$
\left.\begin{array}{c}
\mathrm{k}_{\mathrm{lc} \mid \mathrm{p}_{\mathrm{n}}}=\frac{\mathrm{q}_{\mathrm{Pvd}\left\langle\Delta \mathrm{p}_{\mathrm{Pi}}=\mathrm{p}_{\mathrm{n}}\right.}}{\mathrm{q}_{\mathrm{Pt}}}= \\
=\left[\frac{1}{\mathrm{~B}_{\mid \mathrm{p}_{\mathrm{Plia}} \approx 0.15 \mathrm{MPa}, \vartheta=20{ }^{\circ} \mathrm{C}}\left(1+\mathrm{a}_{\mathrm{p}} \mathrm{p}_{\mathrm{n}}+\mathrm{a}_{\vartheta} \Delta \vartheta\right)}+\right] \mathrm{p}_{\mathrm{n}} \\
+\frac{\varepsilon}{\mathrm{p}_{\text {Plia }}+\mathrm{p}_{\mathrm{n}}}
\end{array}\right]
$$

Therefore, in a displacement pump, operating at theoretical working capacity $\mathrm{q}_{\mathrm{Pt}}$ per one shaft revolution, the working liquid compressibility coefficient $\mathrm{k}_{\mathrm{lc|}_{\mathrm{n}}}$ (formula (20)) is a combined effect of modulus $\mathrm{B}$ of hydraulic oil volume elasticity, oil aeration coefficient $\varepsilon$ and also liquid temperature $\vartheta$ (increase $\Delta \vartheta$ to the reference temperature $\vartheta=20{ }^{\circ} \mathrm{C}$ ) and absolute pressure $\mathrm{p}_{\text {Plia }}$ in the working chambers during their connection with the inlet channel, as well as the system nominal pressure $\mathrm{p}_{\mathrm{n}}$.

In the same displacement pump operating with variable capacity $\mathrm{q}_{\mathrm{Pgv}}$ per one shaft revolution, the value of working liquid compressibility coefficient $\mathrm{k}_{\mathrm{lc|}_{\mathrm{p}}}$ (formula (19)) increases in comparison with the value $\mathrm{k}_{\mathrm{lc}_{\mathrm{n}}}$ during the pump operation with the theoretical working capacity $\mathrm{q}_{\mathrm{Pt}}$. This is an effect of the increased ratio of initial liquid volume $\left(\mathrm{V}_{0}\right.$ in Fig. 6) subjected to compression, i.e. the volume $\left(0.5 \mathrm{q}_{\mathrm{Pt}}+0.5 \mathrm{q}_{\mathrm{Pgv}}\right)$ (formula (8)), to the set working volume $\mathrm{q}_{\mathrm{Pgv}}$. Therefore, decreasing the $\mathbf{q}_{\mathrm{Pgv}}$ setting causes in a variable capacity displacement pump an increase of $\mathbf{k}_{\left.\mathbf{l c |}\right|_{\mathbf{n}}}$ coefficient (formula (19)).

\section{IMPORTANCE OF THE ACCURACY OF EVALUATION OF $q_{\mathrm{Pt}}$ AND $q_{\mathrm{Pgv}}$ FOR THE ACCURACY OF EVALUATION OF THE INTENSITY OF VOLUMETRIC LOSSES AND TORQUE OF MECHANICAL LOSSES IN THE PUMP}

It is important, particularly during investigation of a pump of variable capacity per one shaft revolution, to determine precisely the theoretical capacity $\mathrm{q}_{\mathrm{Pt}}$ per one pump shaft revolution and geometrical capacities $\mathrm{q}_{\mathrm{Pgv}}$ per one pump shaft revolution. Geometrical capacities $\mathrm{q}_{\mathrm{pgv}}$ change in the $0 \leq \mathrm{q}_{\mathrm{Pgv}} \leq \mathrm{q}_{\mathrm{Pt}}$ range and the corresponding coefficients $\mathrm{b}_{\mathrm{P}}=\mathrm{q}_{\mathrm{Pg}} / \mathrm{q}_{\mathrm{Pt}}$ of the pump capacity change in the $0 \leq \mathrm{b}_{\mathrm{P}} \leq 1$ range. Therefore, precise evaluation of the coefficient $\mathrm{b}_{\mathrm{P}}=\mathrm{q}_{\mathrm{Pgv}} / \mathrm{q}_{\mathrm{Pt}}$ depends on the precision of evaluation of $\mathrm{q}_{\mathrm{Pgv}}$ and $\mathrm{q}_{\mathrm{Pt}}$.

The pump theoretical working capacity $\mathrm{q}_{\mathrm{Pt}}$ and geometrical working capacities $\mathrm{q}_{\mathrm{Pgv}}$ are determined at the indicated increase $\Delta \mathrm{p}_{\mathrm{Pi}}$ of pressure in the pump working chambers equal to zero $\left(\Delta \mathrm{p}_{\mathrm{Pi}}=0\right)$; the working capacities are determined by approximation at the point $\Delta \mathrm{p}_{\mathrm{Pi}}=0$ of the line $\mathrm{q}_{\mathrm{P}}=\mathrm{Q}_{\mathrm{P}} / \mathrm{n}_{\mathrm{P}}=$ $=\mathrm{f}\left(\Delta \mathrm{p}_{\mathrm{Pi}}\right)$ describing, at a pump constant setting (but the value of $b_{p}$ coefficient unknown exactly), the capacity $q_{p}$ displaced during one pump shaft revolution as dependent on the indicated increase $\Delta \mathrm{p}_{\mathrm{pi}}$. The line $\mathrm{q}_{\mathrm{p}}=\mathrm{f}\left(\Delta \mathrm{p}_{\mathrm{pi}}\right)$ runs through the measurement points obtained in the investigation.

Fig. 3 presents examples of dependence $\mathrm{q}_{\mathrm{P}}=\mathrm{f}\left(\Delta \mathrm{p}_{\mathrm{pi}}\right)$ of capacity $\mathrm{q}_{\mathrm{p}}$ per one shaft revolution of an axial piston pump on the indicated increase $\Delta \mathrm{p}_{\mathrm{pi}}$ of pressure in the working chambers at the coefficient $b_{\mathrm{P}}=1$ of pump capacity per one shaft revolution $[8,9]$. These are examples of searching the theoretical working capacity $\mathrm{q}_{\mathrm{Pt}}$ per one pump shaft revolution and also the evaluation of subdivision of the intensity $\mathrm{q}_{\mathrm{P}_{\mathrm{v}}}$ of volumetric losses per one shaft revolution into the volumetric loss $\mathrm{q}_{\mathrm{Pvl}}$ due to oil leakage in the working chambers and volumetric loss $\mathrm{q}_{\mathrm{Pvc}}$ due to compressibility of non-aerated (or aerated) oil.

Loss $\mathrm{q}_{\mathrm{Pvc}}=\mathrm{f}\left(\Delta \mathrm{p}_{\mathrm{Pi}}\right)$ per one shaft revolution, determined from formula (13), due to liquid compressibility, occurring at setting $\mathrm{q}_{\mathrm{Pgv}}$ of the pump variable geometrical working capacity (or from formula (14) at setting $\mathrm{q}_{\mathrm{P}_{\mathrm{t}}}$ of the pump theoretical working capacity) is added to capacity $\mathrm{q}_{\mathrm{P}}=\mathrm{f}\left(\Delta \mathrm{p}_{\mathrm{Pi}}\right)$ per one shaft revolution shown by the line running through the test measurement points. The result of adding $\mathrm{q}_{\mathrm{Pvc}_{\mathrm{v}}}=\mathrm{f}\left(\Delta \mathrm{p}_{\mathrm{Pi}}\right)$ to $\mathrm{q}_{\mathrm{P}}=\mathrm{f}\left(\Delta \mathrm{p}_{\mathrm{Pi}}\right)$ is pump capacity $\mathrm{q}_{\mathrm{P} \text { without compressibility }}=\mathrm{f}\left(\Delta \mathrm{p}_{\mathrm{Pi}}\right)$ as a difference between $\mathrm{q}_{\mathrm{Pgv}}\left(\right.$ or $\left.\mathrm{q}_{\mathrm{Pt}}\right)$ and the volumetric loss $\mathrm{q}_{\mathrm{Pvl}}$ due to oil leakage (independent of the liquid compressibility):

$$
\begin{gathered}
\left(\mathrm{q}_{\mathrm{P} \text { without compressibility }}=\mathrm{q}_{\mathrm{Pvc}}+\mathrm{q}_{\mathrm{P}}\right)=\mathrm{f}\left(\Delta \mathrm{p}_{\mathrm{Pi}}\right) \\
\left(\mathrm{q}_{\mathrm{P} \text { without compressibility }}=\mathrm{q}_{\mathrm{Pgv}}\left(\text { or } \mathrm{q}_{\mathrm{Pt}}\right)-\mathrm{q}_{\mathrm{Pvl}}\right)=\mathrm{f}\left(\Delta \mathrm{p}_{\mathrm{Pi}}\right)
\end{gathered}
$$

Approximation of the $\mathrm{q}_{\mathrm{P} \text { without compressibility }}=\mathrm{f}\left(\Delta \mathrm{p}_{\mathrm{P}}\right)$ line at $\Delta \mathrm{p}_{\mathrm{Pi}}=0$ allows to determine the $\mathrm{q}_{\mathrm{Pgv}}\left(\right.$ or $\left.\mathrm{q}_{\mathrm{Pt}}\right)$ :

$$
\mathrm{q}_{\mathrm{P} \text { without compressibility } \mid \Delta \mathrm{pPi}=0}=\mathrm{q}_{\mathrm{Pgv}}\left(\text { or } \mathrm{q}_{\mathrm{Pt}}\right)
$$

As shown in Fig. 3, the pump theoretical working capacities $\mathrm{q}_{\mathrm{Pt}}$, at point $\Delta \mathrm{p}_{\mathrm{Pi}}=0$ of the $\mathrm{q}_{\mathrm{P}}=\mathrm{f}\left(\Delta \mathrm{p}_{\mathrm{Pi}}\right)$ line, obtained from tests and including also the liquid compressibility, as well as of the 


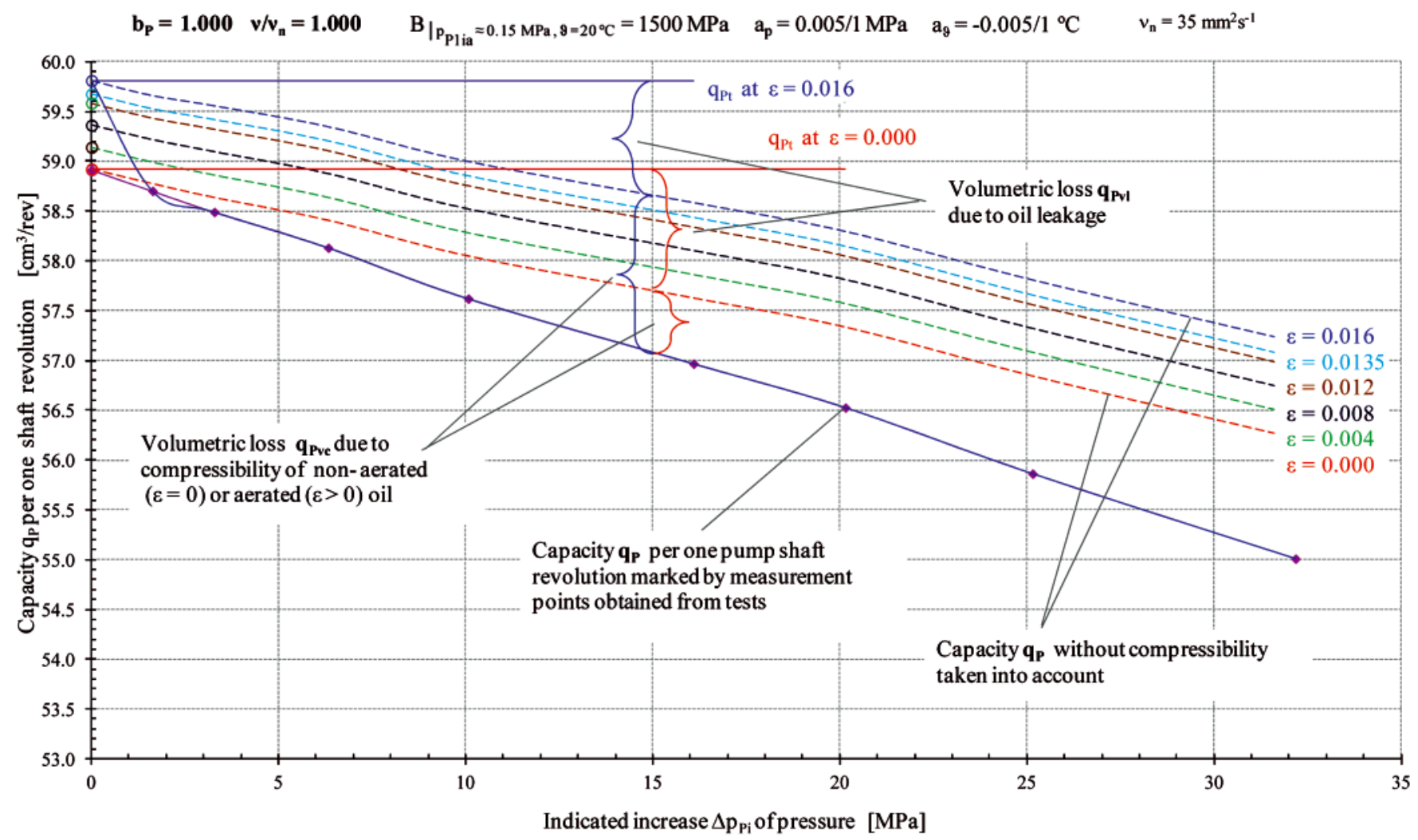

Fig. 3. Dependence of pump capacity $q_{P}$ per one shaft revolution on the indicated increase $\Delta p_{P_{i}}$ of pressure in the working chambers, at the coefficient $b_{P}=1$ of pump capacity; the val-ues $q_{P g v}$ of geomet rical working volume and qPt of theoretical working volume per one shaft revolution (determined at $\left.\Delta p_{P i}=0\right)$ and subdivision of the intensity $q_{P_{v}}=q_{P v l}+q_{P v c}$ of volu-metric losses per one shaft revolution into volumetric loss $q_{P v l}$ due to oil leakage in the cham-bers and volumetric loss $q_{P v c}$ due to compressibility of non-aerated (or aerated) oil dependent on the value of oil aeration coefficient $\varepsilon$ ( $\varepsilon=0$ to 0.016); viscosity coefficient $v / v n=1$, oil temperature $\vartheta=43{ }^{\circ} \mathrm{C}$ (pump of the HYDROMATIK A7V.DR.1.R.P.F.00 type) [8, 9]

$\left(\mathrm{q}_{\mathrm{P} \text { without compressibility }}=\mathrm{q}_{\mathrm{Pvc}}+\mathrm{q}_{\mathrm{P}}\right)=\mathrm{f}\left(\Delta \mathrm{p}_{\mathrm{Pi}}\right)$ line taking into account compressibility of non-aerated $(\varepsilon=0)$ oil, have practically the same value $\mathrm{q}_{\mathrm{Pt}}=58.9 \mathrm{~cm}^{3} / \mathrm{rev}$. Approximation of the $\left(\mathrm{q}_{\mathrm{P} \text { without compressibility }}=\mathrm{q}_{\mathrm{Pvc}}+\mathrm{q}_{\mathrm{P}}\right)=\mathrm{f}\left(\Delta \mathrm{p}_{\mathrm{Pi}}\right)$ line at $\Delta \mathrm{p}_{\mathrm{Pi}}=0$ point, taking into account the aerated oil compressibility, shows an increase of $\mathrm{q}_{\mathrm{Pt}}$ value practically proportional to oil aeration coefficient $\varepsilon$. This is clearly presented in Fig. 4. For example, theoretical working capacity with $\varepsilon=0.0135$, reaches the value $\mathrm{q}_{\mathrm{Pt}}=59.57 \mathrm{~cm}^{3} / \mathrm{rev}$.

Fig. 5 presents the subdivision of volumetric losses $\mathrm{q}_{\mathrm{Pv}}=$ $=\mathrm{f}\left(\Delta \mathrm{p}_{\mathrm{Pi}}\right)$ in the tested pump into loss $\mathrm{q}_{\mathrm{Pvc}}=\mathrm{f}\left(\Delta \mathrm{p}_{\mathrm{Pi}}\right)$ due to liquid compressibility and loss $\mathrm{q}_{\mathrm{Pvl}}=\mathrm{f}\left(\Delta \mathrm{p}_{\mathrm{Pi}}\right)$ due to oil leakage at different values of liquid aeration coefficient $\varepsilon$, with the theoretical working capacity $\mathrm{q}_{\mathrm{Pt}}$ per one pump shaft revolution. The lines of $\mathrm{q}_{\mathrm{Pvl}}=\mathrm{f}\left(\Delta \mathrm{p}_{\mathrm{Pi}}\right)$ loss due to oil leakage do not change at different oil aeration coefficient $\varepsilon$ value, but lines $\mathrm{q}_{\mathrm{Pvc}_{\mathrm{v}}}=\mathrm{f}\left(\Delta \mathrm{p}_{\mathrm{Pi}}\right)$ due to oil compressibility differ clearly, as well as lines $\left(\mathrm{q}_{\mathrm{pv}}=\right.$ $\left.=\mathrm{q}_{\mathrm{Pvl}}+\mathrm{q}_{\mathrm{Pvc}}\right)=\mathrm{f}\left(\Delta \mathrm{p}_{\mathrm{Pi}}\right)$ of volumetric losses $\mathrm{q}_{\mathrm{Pv}}=\mathrm{f}\left(\Delta \mathrm{p}_{\mathrm{Pi}}\right)$ as a sum of $\mathrm{q}_{\mathrm{Pvl}}=\mathrm{f}\left(\Delta \mathrm{p}_{\mathrm{Pi}}\right)$ of loss due to leakage and $\mathrm{q}_{\mathrm{Pvc}}=\mathrm{f}\left(\Delta \mathrm{p}_{\mathrm{Pi}}\right)$ of loss due to liquid compressibility.

During a careful investigation of a displacement pump pressing non-aerated working liquid, the accuracy of determining the theoretical working volume $\mathrm{q}_{\mathrm{Pt}}$ and geometrical working volumes $\mathrm{q}_{\mathrm{Pgv}}$ is of an order of one per mille. Accuracy of estimation of the value of coefficients $b_{\mathrm{P}}$ of pump capacity is then also very high.

The accuracy of evaluation of $\mathrm{q}_{\mathrm{Pt}}$ and $\mathrm{q}_{\mathrm{Pgv}}$ is significantly worse when the working liquid is aerated. This is an effect of

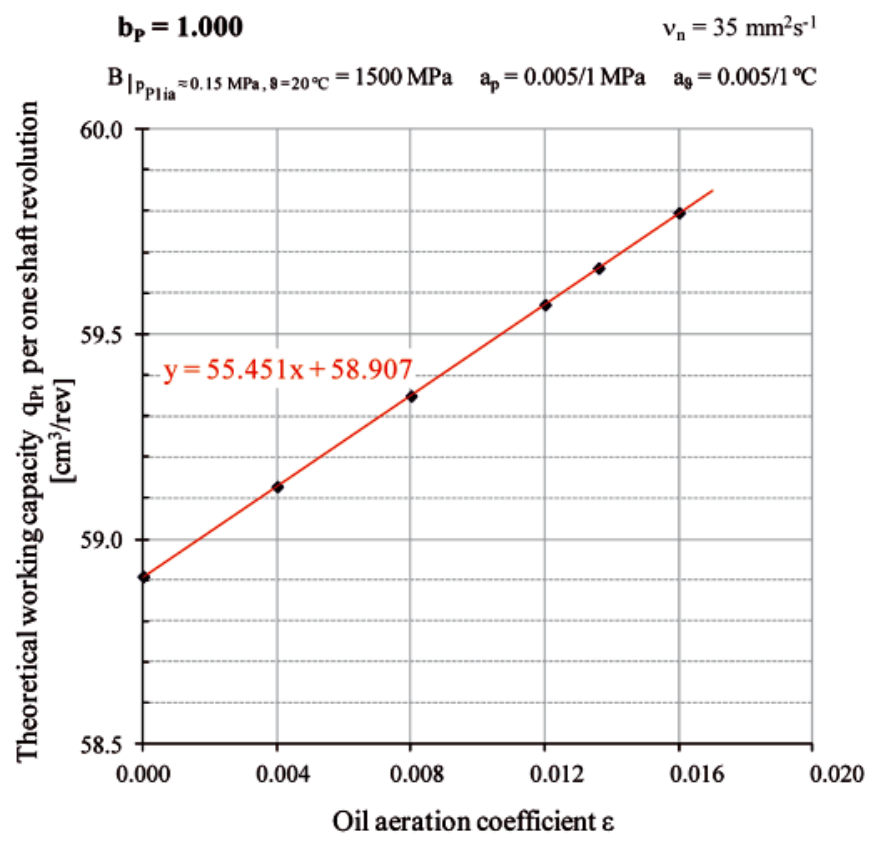

Fig. 4. Effect of evaluation of theoretical working capacity $q_{P t}$ per one pump shaft revolution resulting from assumption of aeration coefficient $\varepsilon$ of the pump displaced oil; evaluation $q_{P t}$ (Fig. 3) is a result of approximation, at $\Delta p_{P i}=0$. of the relation of pump capacity $q_{P}$ per one shaft revolution to the indicated increase $\Delta p_{P i}$ of pressure in the working chambers taking into account the aerated oil compressibility (at a given oil aeration coefficient $\varepsilon$ ) (pump HYDROMATIK A7V.DR.1 .R.P. F.00 type) [8, 9]

the fact, that the aerated liquid in the working chambers filled during their connection with the low-pressure inlet channel decreases its volume because of great compressibility of non- 


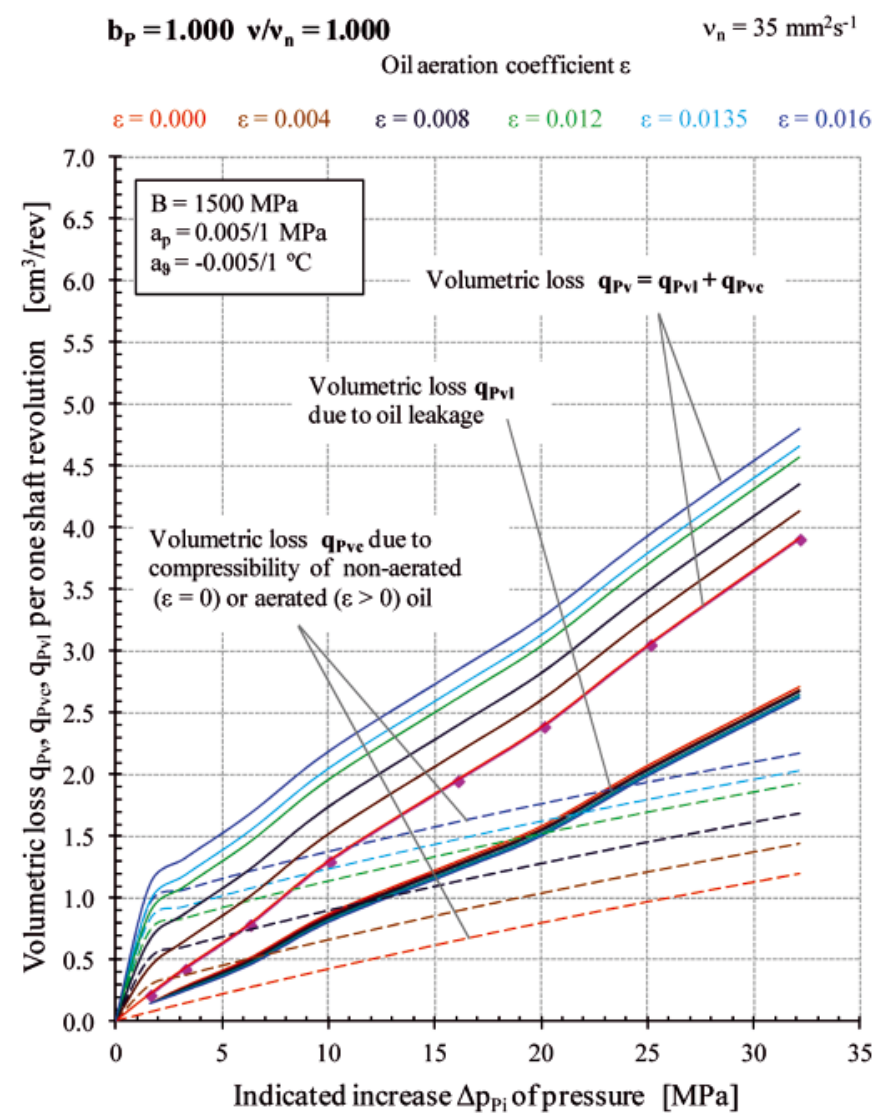

Fig. 5. Subdivision of volumetric loss $q_{P v}=f\left(\Delta p_{P i}\right)$ in the pump into loss $q_{P v c}$ $=f\left(\Delta p_{P i}\right)$ due to oil compressibility and loss $q_{P_{v l}}=f\left(\Delta p_{P_{i}}\right)$ due to oil leakage at different values of oil aeration coefficient $\varepsilon$ and value $v / v_{n}=1$ of oil viscosity coefficient in the tested pump with theoretical working capacity $q_{P t}$ $\left(b_{P}=1\right)$ (pump HYDROMATIK A7V.DR.1.R.P.F.00 type) [8, 9]

dissolved air in the liquid, after connection of the working chambers with the discharge channel where pressure may be only a little higher than in the inlet channel.

Without knowledge of the coefficient $\varepsilon$ of aeration of the liquid flowing into the pump working chambers, it is impossible to determine the quantities $q_{\mathrm{Pt}}$ and $q_{\mathrm{Pgv}}$ precisely.

At the same time, precise knowledge of $\mathrm{q}_{\mathrm{Pt}}$ and $\mathrm{q}_{\mathrm{Pgv}}$ is important in evaluation of the volumetric and mechanical losses in the pump.

The intensity $\mathrm{q}_{\mathrm{Pv}}=\mathrm{Q}_{\mathrm{Pv}} / \mathrm{n}_{\mathrm{P}}$ of volumetric losses $\mathrm{Q}_{\mathrm{Pv}}$ in the pump working chambers per one pump shaft revolution is evaluated as a difference between $\mathrm{q}_{\mathrm{Pt}}\left(\right.$ or $\left.\mathrm{q}_{\mathrm{Pgv}}\right)$ and $\mathrm{q}_{\mathrm{P}}$ determined during the investigation at changing values of the indicated increase $\Delta \mathrm{p}_{\mathrm{Pi}}$ of pressure in the chambers.

Increase $\Delta \mathrm{M}_{\mathrm{Pm} \mid \Delta \mathrm{p}_{\mathrm{Pi}}}$ of the torque of mechanical losses in the pump ,working chambers - shaft" assembly, compared with torque $\mathrm{M}_{\mathrm{Pm} \mid \Delta \mathrm{p}_{\mathrm{Pi}=0}}$ of mechanical losses in the no-load pump, is an effect of increased friction forces in the assembly resulting from the influence of the torque $\mathrm{M}_{\mathrm{Pi}}$ indicated in the working chambers upon the assembly and is proportional to $\mathbf{M}_{\mathrm{Pi}}$.

Increase $\Delta \mathrm{M}_{\mathrm{Pm} \mid \Delta \mathrm{p}_{\mathrm{Pi}}}$ of the torque of mechanical losses in the pump ,working chambers - shaft” assembly is determined during the investigations as a difference $\Delta \mathrm{M}_{\mathrm{Pm} \mid \Delta \mathrm{p}_{\mathrm{Pi}}}=\mathrm{M}_{\mathrm{Pm}}+$ - $\mathrm{M}_{\mathrm{Pm} \mid \Delta \mathrm{p}_{\mathrm{Pi}=0}}$ between torque $\mathrm{M}_{\mathrm{Pm}}$ of losses in the assembly and torque $\mathrm{M}_{\mathrm{Pm} \mid \Delta \mathrm{p}_{\mathrm{Pi}}=0}$ of losses in the assembly of a no-load pump.
Torque $\mathrm{M}_{\mathrm{Pm}}$ of losses is determined as a difference $\mathrm{M}_{\mathrm{Pm}}=$ $=\mathrm{M}_{\mathrm{P}}-\mathrm{M}_{\mathrm{Pi}}$ between torque $\mathrm{M}_{\mathrm{P}}$ measured directly on the shaft and torque $\mathrm{M}_{\mathrm{Pi}}$ indicated in the working chambers. Therefore, extremely important, for determination of torque $M_{\mathrm{Pm}}$ of mechanical losses and of increase $\Delta \mathrm{M}_{\mathrm{Pm} \mid \Delta \mathrm{p}_{\mathrm{Pi}}}$ of torque of mechanical losses, is precision of determination of torque $\mathbf{M}_{\mathrm{Pi}}$ indicated in the working chambers (defined by formulae (35) and (36)).

\section{WORK OF THE DELIVERY OF COMPRESSED WORKING LIQUID DURING ONE PUMP SHAFT REVOLUTION AND TORQUE INDICATED IN THE PUMP WORKING CHAMBERS}

In order to deliver compressed working liquid during one pump shaft revolution, a certain work $\mathbf{E}$ is required, which is a sum of:

- the work of compression itself $-\mathbf{E}_{1}$,

- the work of displacement at constant pressure $-\mathbf{E}_{2}$.

Let's calculate the theoretical values (efficiencies equal to 1) of the two works. For that purpose, the pump delivering the compressed liquid is presented in a simplified way by a piston of cross-section $\mathrm{S}$ moving in a cylinder, which, by two valves $\mathrm{R}_{1}$ and $\mathrm{R}_{2}$ (acting as a distributer), can communicate with, respectively:

- space filled with liquid at constant absolute pressure $\mathrm{p}_{\mathrm{Plia}}$,

- volume $\mathrm{C}_{2}$ filled with liquid at constant absolute pressure

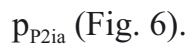

Piston in Fig. 6 performs stroke from position $\mathrm{x}_{\mathrm{o}}$ to the bottom of cylinder i.e. to position 0

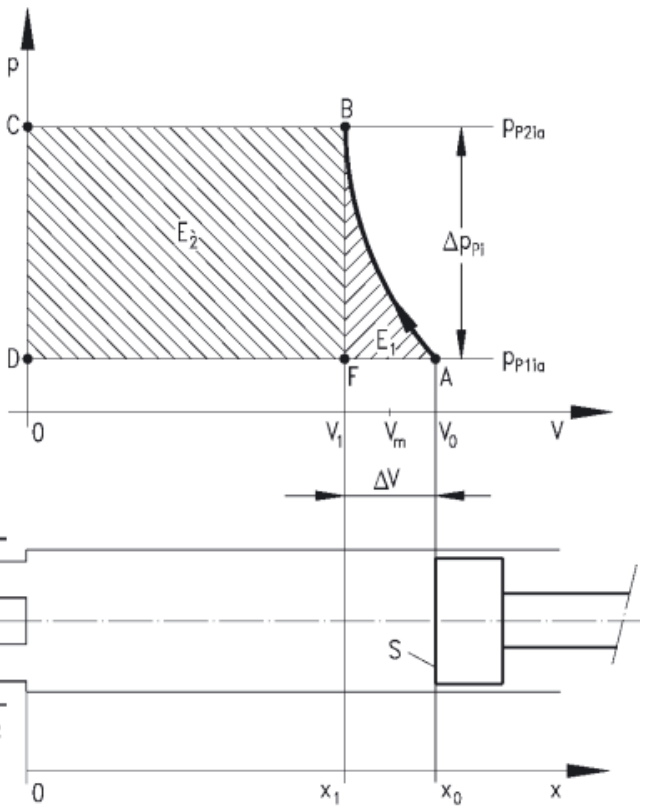

Fig. 6. Work of the delivery of compressed working liquid during one displacement pump shaft revolution (simplified diagram)

Initial position: piston at $\mathrm{x}_{0}$. Volume open to liquid at pressure $\mathrm{p}_{\mathrm{Plia}}: \mathrm{V}_{0} . \mathrm{R}_{1}$ opened, $\mathrm{R}_{2}$ closed. 
1st phase: $R_{1}$ is closed, piston pushed from $x_{0}$ to $x_{1}$ (volume $V_{1}$ ). This is the point where liquid, closed in the cylinder, achieves the pressure $\mathrm{p}_{\mathrm{P} 2 \mathrm{i}}$. The work delivered by the piston is the work of compression:

$$
E_{1}=-\int_{x_{0}}^{x_{1}}\left(p-p_{P l i a}\right) S d x=-\int_{V_{0}}^{V_{1}}\left(p-p_{P 1 \text { ia }}\right) d V
$$

Work $\mathrm{E}_{1}$ is represented by area ABFA.

2nd phase: $R_{2}$ is opened and the piston is pushed (in the case of $b_{P}=q_{P g v} / q_{P t}=1$ ) from $x_{1}$ to 0 . i.e., to the bottom of cylinder. The liquid is discharged into $\mathrm{C}_{2}$. The work delivered by the piston is the work of displacement:

$$
E_{2}=-\int_{x_{1}}^{0}\left(p_{P 2 i a}-p_{P 1 i a}\right) S d x=-\int_{V_{1}}^{0}\left(p_{P 2 i a}-p_{P 1 i a}\right) d V=\left(p_{P 2 i a}-p_{P 1 i a}\right) V_{1}
$$

Work $\mathrm{E}_{2}$ is represented by area BCDFB.

3rd phase: $R_{2}$ is closed, $R_{1}$ opened and we return to the initial position. This operation is carried out without work performed by the pump.

The total work $\mathrm{E}=\mathrm{E}_{1}+\mathrm{E}_{2}$ is represented by the dashed areas in Fig. 6 .

One of the definitions of the modulus B of liquid volume elasticity is the following:

$$
\frac{\Delta \mathrm{V}}{\mathrm{V}}=-\frac{\Delta \mathrm{p}}{\mathrm{B}} \text { where } \mathrm{V}=-\frac{\mathrm{V}}{\mathrm{B}} \mathrm{dp}
$$

Therefore, the compression work is:

$$
E_{2}=-\int_{V_{0}}^{V_{1}}\left(p-p_{1}\right) d V=\int_{p_{1}}^{p_{2}}\left(p-p_{1}\right) \frac{V}{B} d p=\left.\frac{V}{B} \frac{\left(p-p_{1}\right)^{2}}{2}\right|_{p_{1}} ^{p_{2}}
$$

During operation of pump with theoretical capacity $\mathrm{q}_{\mathrm{Pt}}$ per one shaft revolution $\left(\mathrm{b}_{\mathrm{P}}=1\right)$, the change of V (Fig. 6) during compression work in relation to $\mathrm{V}_{0}$ is small. The compression curve may be replaced by linear approximation and the $\mathrm{V}$ quantity in equation (27) by mean value $\mathrm{V}_{\mathrm{m}}=\left(\mathrm{V}_{0}+\mathrm{V}_{1}\right) / 2$ :

Therefore:

$$
E_{1}=\frac{V_{m}}{B} \frac{\left(p_{2}-p_{1}\right)^{2}}{2}
$$

$$
\mathrm{E}_{2}=\mathrm{V}_{1}\left(\mathrm{p}_{\mathrm{P} 2 \mathrm{ia}}-\mathrm{p}_{\mathrm{P} 1 \mathrm{ia}}\right)(\text { acc. to }(25))
$$

and:

$$
\begin{gathered}
\mathrm{E}=\mathrm{E}_{1}+\mathrm{E}_{2}=\left(\mathrm{p}_{2}-\mathrm{p}_{1}\right)\left[\mathrm{V}_{1}+\frac{\mathrm{V}_{\mathrm{m}}\left(\mathrm{p}_{2}-\mathrm{p}_{1}\right)}{2 \mathrm{~B}}\right]=\left(\mathrm{p}_{2}-\mathrm{p}_{1}\right)\left[\mathrm{V}_{1}+\frac{\Delta \mathrm{V}}{2}\right] \\
\mathrm{E}=\left(\mathrm{p}_{2}-\mathrm{p}_{1}\right) \mathrm{V}_{\mathrm{m}} \\
\mathrm{E}=\mathrm{V}_{\mathrm{m}}\left(\mathrm{p}_{\mathrm{P} 2 \text { ia }}-\mathrm{p}_{\mathrm{P} 1 \mathrm{i}}\right)
\end{gathered}
$$

Formula (29) describing the work E may be replaced by the expression:

$$
\mathrm{E}=\left[\mathrm{V}_{0}-\frac{\Delta \mathrm{V}}{2}\right]\left(\mathrm{p}_{\mathrm{P} 2 \mathrm{ia}}-\mathrm{p}_{\mathrm{P} 1 \mathrm{ia}}\right)=\left[\mathrm{V}_{0}-\frac{\Delta \mathrm{V}}{2}\right] \Delta \mathrm{p}_{\mathrm{Pi}}
$$

In a real displacement pump with variable capacity per one shaft revolution, with the geometrical working capacity setting $\mathrm{q}_{\text {Pgv }}$, work E performed by the pump in the working chambers during one shaft revolution (after replacing in formula (30) the original volume $\mathrm{V}_{0}$ by volume $\mathrm{q}_{\mathrm{Pgv}}$, the change $\Delta \mathrm{V}$ of liquid volume due to liquid compressibility by loss $\mathrm{q}_{\mathrm{Pvc}}$ of pump capacity during one shaft revolution (formula (8) and the loss $\mathrm{q}_{\mathrm{Pvc}}$ by formula (11)), is described by the expressions:

$$
\mathrm{E}=\left(\mathrm{q}_{\mathrm{Pgv}}-\frac{\mathrm{q}_{\mathrm{Pvc}}}{2}\right) \Delta \mathrm{p}_{\mathrm{Pi}}
$$

and:

$$
\mathrm{E}=\left\{1-\frac{1}{2}\left[\frac{1}{\mathrm{~B}_{\mid \mathrm{p}_{\mathrm{P} 1 \mathrm{ia}} \approx 0.15 \mathrm{MPa}, \vartheta=20^{\circ} \mathrm{C}}\left(1+\mathrm{a}_{\mathrm{p}} \Delta \mathrm{p}_{\mathrm{Pi}}+\mathrm{a}_{\vartheta} \Delta \vartheta\right)}+\frac{\varepsilon}{\mathrm{p}_{\mathrm{Plia}}+\Delta \mathrm{p}_{\mathrm{Pi}}}\right] \Delta \mathrm{p}_{\mathrm{Pi}}\right\} \mathrm{q}_{\mathrm{Pgv}} \Delta \mathrm{p}_{\mathrm{Pi}}
$$


and with $\mathrm{q}_{\mathrm{Pgv}}=\mathrm{q}_{\mathrm{Pt}}$ (in reference to (12)) by the expressions:

$$
\mathrm{E}=\left(\mathrm{q}_{\mathrm{Pt}}-\frac{\mathrm{q}_{\mathrm{Pvc}}}{2}\right) \Delta \mathrm{p}_{\mathrm{Pi}}
$$

and:

$$
\mathrm{E}=\left\{1-\frac{1}{2}\left[\frac{1}{\mathrm{~B}_{\mathrm{p}_{\mathrm{P} 1 \mathrm{ia}} \approx 0.15 \mathrm{MPa}, \vartheta=20^{\circ} \mathrm{C}}\left(1+\mathrm{a}_{\mathrm{p}} \Delta \mathrm{p}_{\mathrm{Pi}}+\mathrm{a}_{\vartheta} \Delta \vartheta\right)}+\frac{\varepsilon}{\mathrm{p}_{\mathrm{P} 1 \mathrm{ia}}+\Delta \mathrm{p}_{\mathrm{Pi}}}\right] \Delta \mathrm{p}_{\mathrm{Pi}}\right\} \mathrm{q}_{\mathrm{Pt}} \Delta \mathrm{p}_{\mathrm{Pi}}
$$

It has to be mentioned, that in formula (32), describing the work E performed by the pump with setting $\mathrm{q}_{\mathrm{Pgv}}$ per one shaft revolution, the $\mathrm{q}_{\mathrm{Pgv}}$ value is determined by approximation of the $\left(\mathrm{q}_{\mathrm{P}}+\mathrm{q}_{\mathrm{Pvc}}\right)=\mathrm{f}\left(\Delta \mathrm{p}_{\mathrm{Pi}}\right)$ line at point $\Delta \mathrm{p}_{\mathrm{Pi}}=0$. At the same time, the formula (32) contains the value $\mathrm{q}_{\mathrm{Pvc}}=\mathrm{f}\left(\Delta \mathrm{p}_{\mathrm{Pi}}\right)$ describing a loss of capacity per one shaft revolution due to the liquid compressibility taking into account the change $\Delta \mathrm{V}$ (Fig. 6) of liquid volume resulting from the variable capacity pump operation mode, i.e. the compressed volume $\mathrm{V}_{0}$ (Fig. 6) equal to $\mathrm{V}_{0}=0.5 \mathrm{q}_{\mathrm{Pt}}+0.5 \mathrm{q}_{\mathrm{Pgv}}$.

Torque $\mathrm{M}_{\mathrm{Pi}}$ indicated in the pump working chambers, corresponding to work $\mathrm{E}$ in the chambers during one shaft revolution, is then, with $\mathrm{q}_{\mathrm{Pgv}}$ setting, described by the formula:

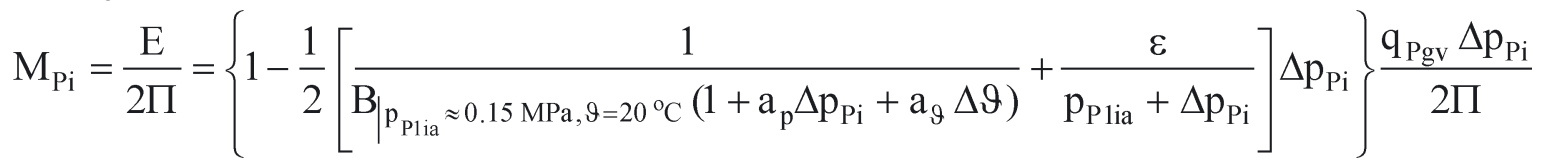

and with $\mathrm{q}_{\mathrm{Pgv}}=\mathrm{q}_{\mathrm{Pt}}$ by the formula:

$$
\mathrm{M}_{\mathrm{Pi}}=\frac{\mathrm{E}}{2 \Pi}=\left\{1-\frac{1}{2}\left[\frac{1}{\mathrm{~B} \mathrm{p}_{\mathrm{Plia}} \approx 0.15 \mathrm{MPa}, \vartheta=20^{\circ} \mathrm{C}\left(1+\mathrm{a}_{\mathrm{p}} \Delta \mathrm{p}_{\mathrm{Pi}}+\mathrm{a}_{\vartheta} \Delta \vartheta\right)}+\frac{\varepsilon}{\mathrm{p}_{\mathrm{Plia}}+\Delta \mathrm{p}_{\mathrm{Pi}}}\right] \Delta \mathrm{p}_{\mathrm{Pi}}\right\} \frac{\mathrm{q}_{\mathrm{Pt}} \Delta \mathrm{p}_{\mathrm{Pi}}}{2 \Pi}
$$

\section{METHOD OF DETERMINING THE WORKING LIQUID AERATION COEFFICIENT $\varepsilon$}

As it so far has not been possible to determine the coefficient $\varepsilon$ of aeration of the working liquid flowing into the pump, and therefore not possible to take the liquid compressibility into account, both at the small increase $\Delta \mathrm{p}_{\mathrm{Pi}}$ of pressure in the pump working chambers and in the full range of increase $\Delta \mathrm{p}_{\mathrm{Pi}}$ of pressure - up to the hydrostatic drive system nominal pressure $\mathrm{p}_{\mathrm{n}}$, the pictures of volumetric losses and mechanical losses in the pump, determined by the applied methods, are deformed. For instance, if the compressibility of working liquid, the liquid in fact aerated, is not taken into account, a picture of negative increase $\Delta \mathrm{M}_{\mathrm{Pm} \mid \Delta \mathrm{p}_{\mathrm{Pi}}}$ of torque of mechanical losses in the pump ,working chambers - shaft" assembly is obtained as an effect of increased torque $\mathrm{M}_{\mathrm{Pi}}$ indicated in the working chambers due to the increase of geometrical working volume $\mathrm{q}_{\mathrm{Pgv}}$ (of $\mathrm{b}_{\mathrm{P}}$ coefficient), which is an illogical result (Fig. 7).

A method of determining the coefficient $\varepsilon$ of working liquid aeration may be searching for value of $\varepsilon$ which was used for determining the values $q_{P g v}$ of geometrical working capacities causing an increase $\mathbf{M}_{\mathrm{Pm} \mid \Delta \mathrm{p}_{\mathrm{Pi}}}$ of torque of mechanical losses in the pump ,working chambers - shaft” assembly proportional to torque $\mathrm{M}_{\mathrm{Pi}}$ indicated in the working chambers (formula (35)), a torque $M_{\mathrm{Pi}}$ resulting from $\mathbf{q}_{\mathrm{Pgv}}$ and from $\varepsilon$ at the constant value $\Delta \mathbf{p}_{\mathrm{Pi}}$ of indicated increase of pressure in the chambers. It is assumed, that during searching for $\mathrm{q}_{\mathrm{Pgv}}$ and $\varepsilon$, the increase $\mathrm{M}_{\mathrm{Pm}_{\mid \Delta \mathrm{P}_{\mathrm{P}}}}$ of the torque of mechanical losses is determined at a constant value of indicated increase $\Delta \mathrm{p}_{\mathrm{Pi}}$ of pressure in the pump working chambers equal to the system nominal pressure $\mathrm{p}_{\mathrm{n}}\left(\Delta \mathrm{p}_{\mathrm{Pi}}=\mathrm{p}_{\mathrm{n}}\right)$.

Therefore, it is assumed, that with a fixed value $\Delta \mathbf{p}_{\mathrm{Pi}}=\mathbf{p}_{\mathrm{n}}$ of the indicated increase of pressure in the pump working chambers, the increasing torque $\mathrm{M}_{\mathrm{Pi}}$ in the chambers (formula (35)), described by the expression:

$$
\mathbf{M}_{\mathrm{Pi}}=\left\{1-\frac{1}{2}\left[\frac{1}{\mathbf{B}_{\mathbf{p}_{\mathrm{P} 1 \mathrm{i}} \approx 0.15 \mathrm{MPa}, \vartheta=20^{\circ} \mathrm{C}}\left(1+\mathbf{a}_{\mathbf{p}} \mathbf{p}_{\mathbf{n}}+\mathbf{a}_{\vartheta} \Delta \vartheta\right)}+\frac{\varepsilon}{\mathbf{p}_{\mathrm{Plia}}+\mathbf{p}_{\mathbf{n}}}\right] \mathbf{p}_{\mathbf{n}}\right\} \frac{\mathbf{q}_{\mathrm{Pgv}} \mathbf{p}_{\mathbf{n}}}{2 \Pi}
$$

must be accompanied by proportional increase $\Delta \mathrm{M}_{\mathrm{Pm}_{\mathrm{m}} \mid \Delta \mathrm{p}_{\mathrm{Pi}}=\mathrm{p}_{\mathrm{n}}}$ of torque of mechanical losses in the pump ,working chambers - shaft" assembly:

$$
\begin{gathered}
\Delta M_{P m \mid \Delta p_{P i}=p_{n} ; q_{P g v}} \sim M_{P i \mid \Delta p_{P i}=p_{n} ; q_{P g v}} \\
\Delta M_{P m \mid \Delta p_{P i}=p_{n} ; q_{P g v}} \sim q_{P g v}\left(b_{P}\right)
\end{gathered}
$$


With fixed values of $\mathrm{B}, \mathrm{a}_{\mathrm{p}}, \mathrm{a}_{\vartheta}, \vartheta, \mathrm{p}_{\mathrm{Plia}}$ and $\mathrm{p}_{\mathrm{n}}$, expressions (38) and (39) can be obtained only with one value $\varepsilon$ of the aeration coefficient, which was assumed for determining of $\mathrm{q}_{\mathrm{Pgv}}$ values and of the pump capacity $\mathrm{b}_{\mathrm{P}}$ coefficient values.

Fig. 7 presents results of searching for the oil aeration coefficient $\varepsilon$ during pump tests $[8,9]$.

With the assumption of non-compressible $(\mathrm{B}=\infty)$ and non-aerated $(\varepsilon=0)$ liquid, i.e. with the assumption of the liquid compressibility coefficient $\mathrm{k}_{\mathrm{lc|} \mathrm{p}_{\mathrm{n}}}=0$ the picture of $\Delta \mathrm{M}_{\mathrm{Pm}_{\mid \mathrm{p}} \mathrm{p}_{\mathrm{Pi}}=\mathrm{p}_{\mathrm{n}}}=$ $=\mathrm{f}\left(\mathrm{M}_{\mathrm{Pi} \mid \Delta \mathrm{p}_{\mathrm{Pi}}=\mathrm{p}_{\mathrm{n}}}\right)$ relation has the form of a descending straight line:

from value $\Delta \mathrm{M}_{\mathrm{Pm}}=1.87 \mathrm{Nm}$ at $\mathrm{q}_{\mathrm{Pgv}}=0$

to value $\Delta \mathrm{M}_{\mathrm{Pm}}=0.53 \mathrm{Nm}$ at $\mathrm{q}_{\mathrm{Pgv}}=\mathrm{q}_{\mathrm{Pt}}$.

With the assumption of compressible and non-aerated $(\varepsilon=0)$ liquid, the picture of $\Delta \mathrm{M}_{\mathrm{Pm} \mid \Delta \mathrm{p}_{\mathrm{Pi}}=\mathrm{p}_{\mathrm{n}}}=\mathrm{f}\left(\mathrm{M}_{\mathrm{P}_{\mathrm{i} i} \Delta \mathrm{p}_{\mathrm{Pi}_{\mathrm{i}}}=\mathrm{p}_{\mathrm{n}}}\right)$ relation has the form of an ascending straight line:

from value $\Delta \mathrm{M}_{\mathrm{Pm}}=1.86 \mathrm{Nm}$ at $\mathrm{q}_{\mathrm{Pgv}}=0$

to value $\Delta \mathrm{M}_{\mathrm{Pm}}=2.79 \mathrm{Nm}$ at $\mathrm{q}_{\mathrm{Pgv}}=\mathrm{q}_{\mathrm{Pt}}$.

With the assumption of compressible and aerated $(\varepsilon=0.008)$ liquid, the picture of $\Delta \mathrm{M}_{\mathrm{Pm}_{\mid} \mid \Delta \mathrm{p}_{\mathrm{Pi}}=\mathrm{p}_{\mathrm{n}}}=\mathrm{f}\left(\mathrm{M}_{\mathrm{Pi} \mid \Delta \mathrm{p}_{\mathrm{Pi}}=\mathrm{p}_{\mathrm{n}}}\right)$ relation has the form of an ascending straight line:

from value $\Delta \mathrm{M}_{\mathrm{Pm}}=0.76 \mathrm{Nm}$ at $\mathrm{q}_{\mathrm{Pgv}}=0$

to value $\quad \Delta \mathrm{M}_{\mathrm{Pm}}=1.77 \mathrm{Nm}$ at $\mathrm{q}_{\mathrm{Pgv}}=\mathrm{q}_{\mathrm{Pt}}$.

With the assumption of compressible and aerated $(\varepsilon=0.016)$ liquid, the picture of $\Delta \mathrm{M}_{\mathrm{Pm} \mid \Delta \mathrm{p}_{\mathrm{Pi}}=\mathrm{p}_{\mathrm{n}}}=\mathrm{f}\left(\mathrm{M}_{\mathrm{Pi} \mid \Delta \mathrm{p}_{\mathrm{Pi}}=\mathrm{p}_{\mathrm{n}}}\right)$ relation has the form of an ascending straight line:

from value $\Delta \mathrm{M}_{\mathrm{Pm}}=-0.35 \mathrm{Nm}$ at $\mathrm{q}_{\mathrm{Pgv}}=0$

to value $\quad \Delta \mathrm{M}_{\mathrm{Pm}}=0.74 \mathrm{Nm}$ at $\mathrm{q}_{\mathrm{Pgv}}=\mathrm{q}_{\mathrm{Pt}}$.
With the oil aeration coefficient $\varepsilon=0.0135$, the picture $\Delta \mathrm{M}_{\mathrm{Pm} \mid \Delta \mathrm{p}_{\mathrm{Pi}_{\mathrm{i}}}=\mathrm{p}_{\mathrm{n}} ; \mathrm{q}_{\mathrm{Pgv}}}=\mathrm{f}\left(\mathrm{M}_{\mathrm{Pi}_{\mathrm{i}} \mid \Delta \mathrm{p}_{\mathrm{Pi}}=\mathrm{p}_{\mathrm{n}} ; \mathrm{q}_{\mathrm{Pgv}}}\right)$ has the form of an ascending straight line:

from value $\Delta \mathrm{M}_{\mathrm{Pm}}=0$ at $\mathrm{q}_{\mathrm{Pgv}}=0$

to value $\Delta \mathrm{M}_{\mathrm{Pm}}=1.03 \mathrm{Nm}$ at $\mathrm{q}_{\mathrm{Pgv}}=\mathrm{q}_{\mathrm{Pt}}$.

Figure 8 presents, in reference to results presented in figure 7, a linear relation of the increase $\Delta \mathrm{M}_{\mathrm{Pm} \mid \Delta \mathrm{p}_{\mathrm{Pi}}=\mathrm{p}_{\mathrm{n}} ; \mathrm{q}_{\mathrm{pgv}}=0}$ of torque of mechanical losses to the assumed value of the oil aeration coefficient $\varepsilon$. The relation shown in figure 8 allows to find with high accuracy the value of oil aeration coefficient $\varepsilon$, with which the increase $\Delta M_{\mathrm{Pm} \mid \Delta \mathrm{p}_{\mathrm{Pi}}}=\mathrm{p}_{\mathrm{n}} ; \mathrm{q}_{\mathrm{Pgv}}=0$ of the torque of mechanical losses at $q_{P g v}=0\left(b_{P}=0\right)$ equals zero:

$$
\Delta \mathbf{M}_{\mathbf{P m} \mid \Delta \mathbf{p}_{\mathrm{Pi}}=\mathbf{p}_{\mathbf{n}} ; \mathbf{q}_{\mathrm{Pgv}}=0 ; \varepsilon}=\mathbf{0}
$$

The oil aeration coefficient $\varepsilon$ during the pump testing (pump HYDROMATIK A7V.DR.1.R.P.F.00 type) corresponding to the situation described by formula (40), had the value $\boldsymbol{\varepsilon}=\mathbf{0 . 0 1 3 5}[8,9]$.

\section{CONCLUSIONS}

1. The Author concludes, that there is a possibility of determining a concrete value of the liquid aeration coefficient $\varepsilon$ during the pump operation by finding such value of $\varepsilon$ with which the increase $\Delta \mathrm{M}_{\mathrm{Pm} \mid \Delta \mathrm{p}_{\mathrm{p}_{\mathrm{i}}}=\mathrm{p}_{\mathrm{n}} ; \mathrm{q}_{\mathrm{pgv}}}$ of torque of mechanical losses is proportional to the indicated torque $\Delta \mathrm{M}_{\mathrm{Pm} \mid \Delta \mathrm{p}_{\mathrm{Pi}}=\mathrm{p}_{\mathrm{n}} ; \mathrm{q}_{\mathrm{Pgv}}}$ determined with a fixed value $\Delta \mathrm{p}_{\mathrm{Pi}}=$ cte of increase of pressure in the pump working chambers.

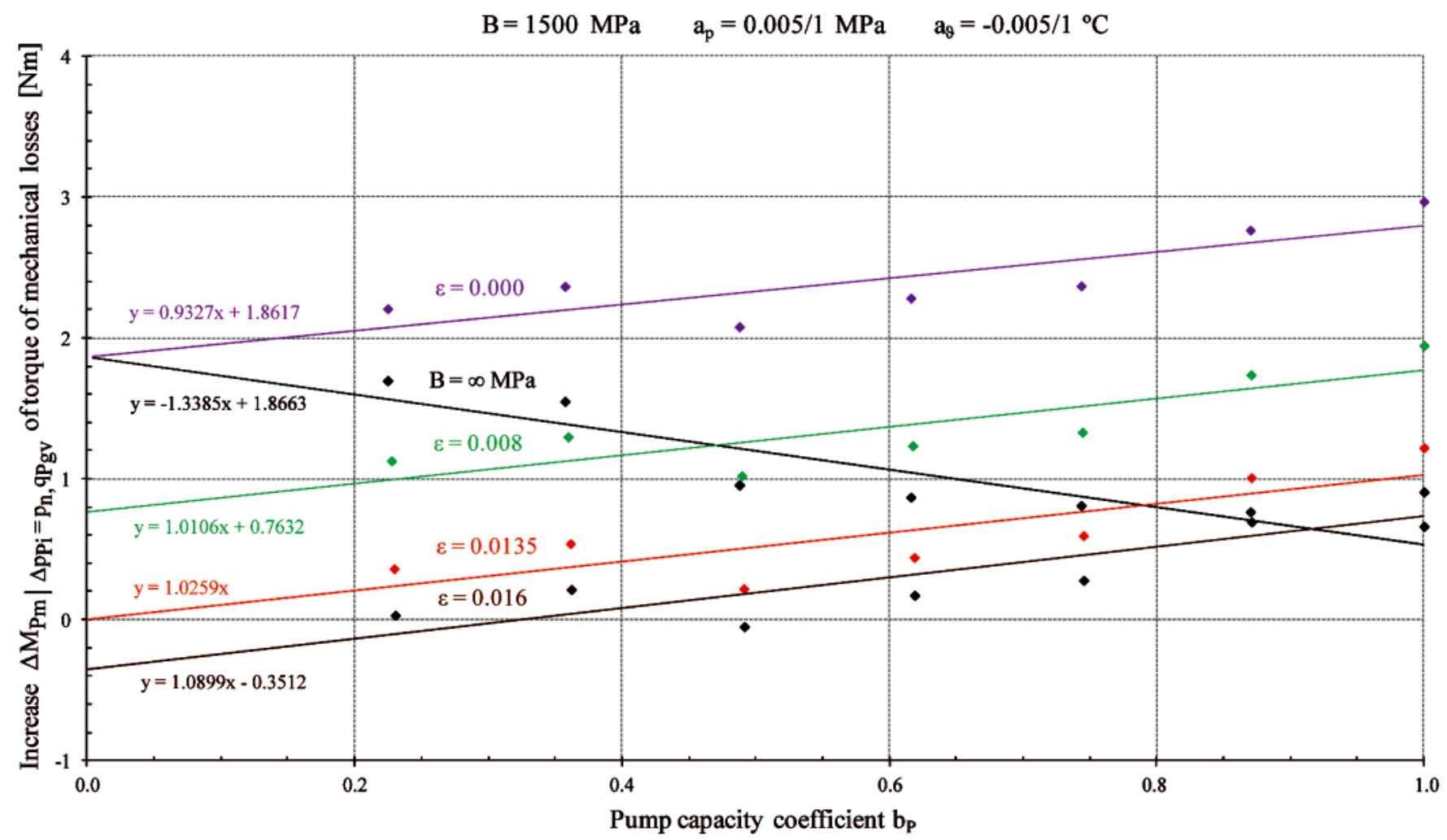

Fig. 7. Picture of the relations of increase $\triangle M_{P m \mid \Delta p_{P i}}=32 \mathrm{MPa} ; q_{P g v}$ of torque of mechanical losses in the pump ,working chambers - shaft" assembly (pump HYDROMATIK A7V.DR.1.R.P.F.00 type) to the geometrical working capacity $q_{P g v}\left(b_{P}\right.$ coefficient) with assumed values of modulus $B$ of hydraulic oil elasticity and oil aeration coefficient $\varepsilon$; the line $\Delta M_{P m \mid \Delta p_{P i}}=32 \mathrm{MPa} ; q_{P g v}$ corresponding to $\varepsilon=0.0135$ is an effect of the straight line picture presented in Fig. 8 [8, 9] 


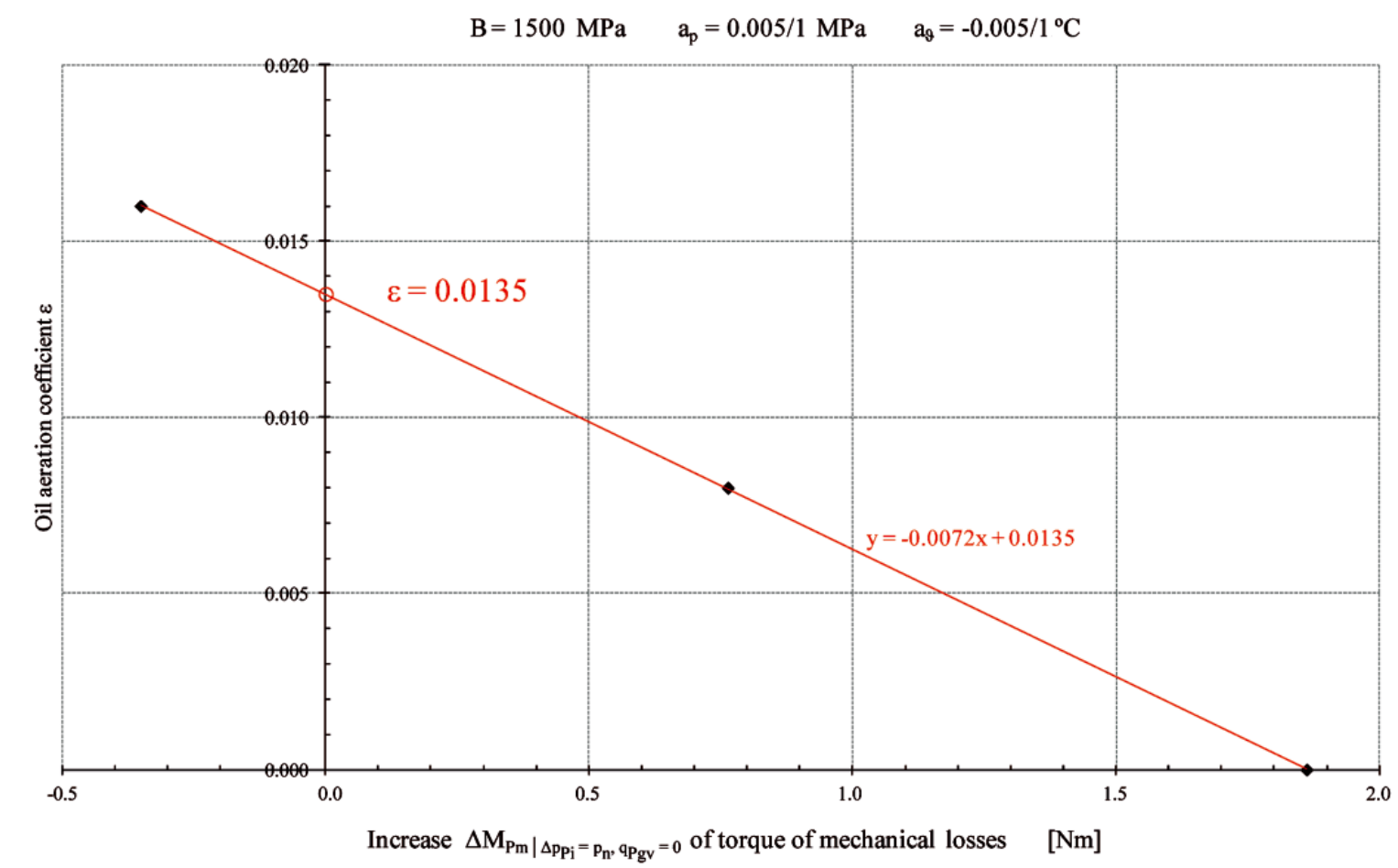

Fig. 8. Straight line relation of the oil aeration coefficient $\varepsilon$ to the assumed increase $\Delta M_{P m \mid \Delta p_{P i}}=32 \mathrm{MPa} ; q_{P g v}=0$ of torque of mechanical losses (pump HYDROMATIK A7V.DR.1.R.P.F.00 type) [8, 9]

2. The fixed value $\Delta \mathrm{p}_{\mathrm{Pi}}$ assumed in searching the liquid aeration coefficient $\varepsilon$ equals to the nominal pump operation pressure $\mathrm{p}_{\mathrm{n}}\left(\Delta \mathrm{p}_{\mathrm{Pi}}=\mathrm{cte}=\mathrm{p}_{\mathrm{n}}\right)$.

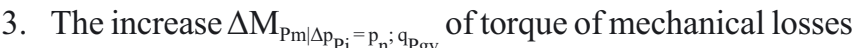
with a fixed value of $\Delta \mathrm{p}_{\mathrm{Pi}}\left(\Delta \mathrm{p}_{\mathrm{Pi}}=\right.$ cte $)$ is proportional to the pump geometrical working capacity $\mathrm{q}_{\mathrm{Pgv}}$, therefore:

only with taking into account the aeration coefficient $\varepsilon$

of liquid displaced by the pump the relation

$\Delta \mathrm{M}_{\mathrm{Pm} \mid \Delta \mathrm{p}_{\mathrm{Pi}}}=\mathrm{p}_{\mathrm{n}} ; \mathrm{q}_{\mathrm{Pgv}} \sim \mathrm{q}_{\mathrm{Pgv}}$ can be obtained from tests.

4. The method, proposed by the Author, of determining the working liquid aeration coefficient $\varepsilon$, is presented in this paper and has been practically applied for the first time by Jan Koralewski in his investigations of the influence of viscosity and compressibility of aerated hydraulic oil on volumetric and mechanical losses in a pump of HYDROMATIK A7V.58.1.R.P.F.00 type [8, 9].

\section{BIBLIOGRAPHY}

1. Paszota Z.: Effect of the working liquid compressibility on the picture of volumetric and mechanical losses in a high pressure displacement pump used in a hydrostatic drive. Part I Energy losses in a drive system, volumetric losses in a pump //International Scientific-Technical Conference Hydraulics and Pneumatics, Wrocław, 16 - 18 maja 2012 / Ośrodek Doskonalenia Kadr SIMP - Wrocław : ODK SIMP we Wrocławiu, 2012,

2. Paszota Z.: Effect of the working liquid compressibility on the picture of volumetric and mechanical losses in a high pressure displacement pump used in a hydrostatic drive. Part II Mechanical losses in a pump //International Scientific-Technical Conference Hydraulics and Pneumatics, Wrocław, 16 - 18 maja 2012 / Ośrodek Doskonalenia Kadr SIMP - Wrocław : ODK SIMP we Wrocławiu, 2012,

3. Paszota Z.: Effect of the working liquid compressibility on the picture of volumetric and mechanical losses in a high pressure displacement pump used in a hydrostatic drive. Part I Energy losses in a drive system, volumetric losses in a pump // Polish Maritime Research, Vol. 19, 2/2012

4. Paszota Z.: Effect of the working liquid compressibility on the picture of volumetric and mechanical losses in a high pressure displacement pump used in a hydrostatic drive. Part II Mechanical losses in a pump // Polish Maritime Research, Vol. 19 3/2012

5. Paszota Z.: Theoretical and mathematical models of the torque of mechanical losses in the pump used in a hydrostatic drive. (in Polish). Chapter in the monograph: „Research, design, production and operation of hydraulic systems" (in Polish) Adam Klich, Antoni Kozieł and Edward Palczak editors. „Cylinder” Library. „Komag” Mining Mechanisation Centre, Gliwice 2011

6. Paszota Z.: Theoretical and mathematical models of the torque of mechanical losses in the pump used in a hydrostatic drive. (in Polish). „Napędy i sterowanie”, scientific monthly 10/2011

7. Paszota Z.: Theoretical and mathematical models of the torque of mechanical losses in the pump used in a hydrostatic drive. Polish Maritime Research, Vol. 18, 4/2011

8. Koralewski J.: Effect of the liquid viscosity on the energy characteristics of variable capacity piston pump (in Polish). Doctor dissertation (continued). Gdańsk University of Technology, Faculty of Ocean Engineering and Ship Technology

9. Koralewski J.: Effect of oil viscosity and compressibility on determination of volumetric losses in a variable capacity piston pump (In Polish). Paper submitted to the „Cylinder” 2013 Conference. Centrum Mechanizacji Górnictwa „Komag”, Gliwice 2013

10.Guillon M.: Theory and calculation of hydraulic systems (in Polish). Wydawnictwa Naukowo-Techniczne Warszawa 1967

\section{CONTACT WITH THE AUTHOR}

Prof. Zygmunt Paszota

Faculty of Ocean Engineering and Ship Technology

Gdansk University of Technology Narutowicza 11/12

80-233 Gdansk, POLAND

e-mail: zpaszota@pg.gda.pl 